\title{
INTERNATIONAL COMPETITION IN VERTICALLY DIFFERENTIATED MARKETS WITH INNOVATION AND IMITATION: TRADE POLICY VERSUS FREE TRADE
}

\section{Eugen Kováč Krešimir Žigić}
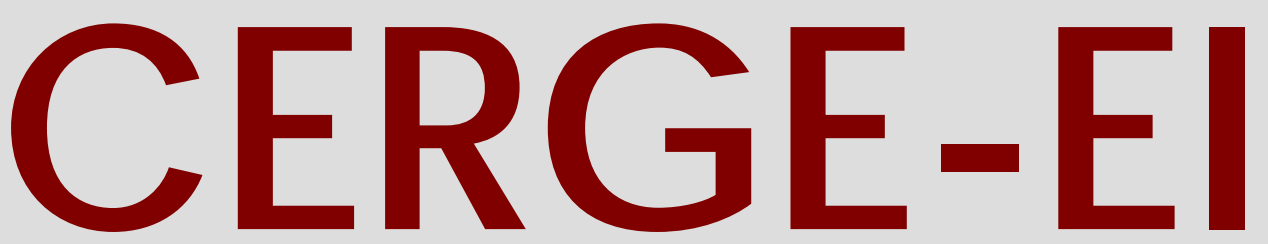

Charles University CenterforEconomic Research and Graduate Education Academy of Sciences of the Czech Republic Ec onomic s Institute 


\section{Working Paper Series 336 (ISSN 1211-3298)}

\section{International Competition in Vertically Differentiated Markets with Innovation and Imitation: Trade Policy versus Free Trade}

Eugen Kováč

Krešimir Žigić

CERGE-EI

Prague, August 2007 
ISBN 978-80-7343-135-8 (Univerzita Karlova. Centrum pro ekonomický výzkum a doktorské studium)

ISBN 978-80-7344-124-1 (Národohospodářský ústav AV ČR, v.v.i.) 


\title{
International Competition in Vertically Differentiated Markets with Innovation and Imitation: Trade Policy versus Free Trade*
}

\author{
Eugen Kováč a;b Krešimir Žigićc
}

\begin{abstract}
August 2007
Abstract

The important characteristic of international competition between developed and less developed countries is vertical product differentiation, where firms' quality choices represent strategic decisions. Unlike the previous literature, we allow for a leadership in quality choice and the possibility of imitation and learning by the domestic firm. We compare both positive and normative aspects of this setup in the free trade and the strategic trade policy regime and show that the value of leadership may change dramatically when moving from free trade to trade policy. We also identify conditions under which trade policy can initiate the change in the quality ladders (known as quality reversal) and demonstrate that such a policy has a somewhat limited scope to achieve it. Thus, free trade can still be an optimal trade arrangement.
\end{abstract}

\begin{abstract}
Abstrakt
Důležitou charakteristikou mezinárodního obchodu mezi rozvinutými a méně rozvinutými zeměmi je vertikální diferenciace produktů, přičemž kvalita je strategickým rozhodnutím firem. Na rozdíl od literatury uvažujeme vůdcovství ve výběru kvalit a možnost imitace. Porovnáváme kladné i normativní aspekty volného obchodu a strategického výběru obchodní politiky. Identifikujeme podmínky, při kterých obchodní politika může vést $\mathrm{k}$ opačnému uspořádání kvalit a ukazujeme, že taková politika na to někdy není dostačující. Proto může být i volný obchod optimálním obchodním uspořádáním
\end{abstract}

Keywords: vertical differentiation, free trade, strategic trade policy, quality rever-sal, leadership, imitation JEL classification: D43, F12, F13, L13

\footnotetext{
*We thank Levent Celik and Avner Shaked for helpful comments. The financial support of the Global Development Network (GDN) Grant is gratefully acknowledged. All errors are ours.

aDepartment of Economics, University of Bonn, Adenauerallee 24-42, 53113 Bonn, Germany; e-mail: eugen.kovac@uni-bonn.de; URL: www.uni-bonn.de/ kovac

${ }^{b}$ CERGE-EI is a joint workplace of the Center for Economic Research and Graduate Education, Charles University, and the Economics Institute of Academy of Sciences of the Czech Republic.

Address: CERGE-EI, P.O. Box 882, Politických vězňů 7, Prague 1, 111 21, Czech Republic
} 


\section{Introduction}

Contrary to the prediction of the standard international trade theory, it is often the case that firms from countries at rather different stages of development compete in the same oligopolistic market (Schott 2004, Hallak 2006). The products produced by firms from developed countries (DCs) are usually associated with a variety of higher quality than the ones produced by firms from less developed countries (LDCs). ${ }^{1}$ Firms' choices of qualities are, however, endogenous and may be influenced by some governmental policies. For instance, a policy maker designing a trade policy for such an oligopolistic market may affect the corresponding firms' choice of qualities. Thus, she may, therefore, need to take into account the strategic behavior of competing firms, and in particular, their choices of qualities. Recent trade literature has already started to explore strategic trade policies in markets with vertically differentiated products. A striking phenomenon in such markets is quality reversal, which occurs when the trade policy reverses the equilibrium ranking of qualities. The existing literature, however, does not address two important aspects of quality choice in the context of DC and LDC - leadership and imitation - nor does it explicitly compare the domestic welfare of free trade with the domestic welfare resulting from such a trade policy. The firms from developed countries are usually technological leaders undertaking $\mathrm{R} \& \mathrm{D}$ or investments in order to innovate their products of higher quality and different design or to invent better production processes, while LDC firms tend to imitate these product and processes. To support these endeavors, the governments of LDCs (or former LDCs like Japan) used to endorse a whole spectrum of "non-conventional" polices from the arsenal of trade and industrial policy. For instance, as noted by Rodrik (2001), governments in the Republic of Korea and Taiwan freely resorted to unorthodox strategies and protected their home markets to raise profits by implementing various industrial and protectionist trade policies and encouraged their firms to reverse-engineer foreign patented products.

Our aim is to fill the above mentioned gap in the literature by intro-

\footnotetext{
${ }^{1}$ In industries like automobiles, electronics, computer hardware and cosmetics, the products from Japan, the USA and Europe are associated with higher qualities than products from East Asia (Ghosh and Das 2001). See also Greenway, Hine and Milner (1994), and Clark and Stanley (1999) for empirical findings.
} 
ducing leadership and imitation into the vertical differentiation model of international trade and by analyzing under which circumstances trade policy improves the domestic welfare vis-à-vis free trade in such a setup. Thus, we study a mutual impact and interaction between leadership and imitation on the one side and a trade policy of LDC, on the other. More specifically, the key issue is, whether and under which conditions can trade policy of LDCs deprive the DC firm from its initial leadership position of producing a higher quality product. Or, to put it in a jargon, we are interested under which conditions the optimal trade policy of LDC leads to quality reversal and what are the domestic welfare consequences of trade policy in general, and of quality reversal in particular. The benchmark against which we evaluate the domestic welfare consequences of trade policy is, of course, free trade.

The existing international trade literature of vertical product differentiation considers the firms' investment in qualities to take place simultaneously (see Subsection 1.1). By introducing leadership explicitly, we abandon this assumption. Thus, the DC firm is assumed to be a leader in quality, that is, it chooses its quality before the LDC firm. ${ }^{2}$ Besides leadership, we introduce the possibility of imitation by the LDC firm (follower). In practice, imitation is frequently used by firms from LDCs that try to "copy" the products from DCs, and that it obviously reduces the costs of innovation. Finally, trade policy takes a rather simple form of import tariff. Imposing import tariffs seems to be the most common and the most practical form of trade policy in LDCs, see for instance, Bhattacharjea (1995) and Ionaşcu and Žigić (2005b). The size of the tariff is chosen after both the domestic firms' imitation stage (second stage) and the leader R\&D investment stage (first stage), but precedes the last, pricing stage (fourth stage). This seems to be a suitable timing assumption in this context due to the fact that the LDC governments may lack the commitment capability. Moreover, trade policy is by its nature of second-best (or even third-best) character, and, consequently, it is plagued with the time consistency problem. ${ }^{3}$ The above timing takes into account

\footnotetext{
${ }^{2}$ The sequential choice of qualities has already been studied in the traditional industrial organization literature (Aoki and Prusa 1997, Lehmann-Grube 1997, Hoppe and Lehmann-Grube 2001). By addressing leadership, our paper also complements the emerging literature on market leaders (Etro 2004, 2006a, 2006b, Kováć, Vinogradov and Žigić 2007).

${ }^{3}$ See, for instance, Staiger (1995) and survey of related literature of this issue there.
} 
these phenomena, and the tariff that we calculate below is, in fact, a time consistent tariff. ${ }^{4}$

Apparently, the action takes place in the domestic, LDC market and the strategic choice considered is the firms' selection of product qualities. The standard assumption in both horizontal and vertical differentiation setup is that firms make a sunk cost investment (e.g., in R\&D or technological improvements) in order to achieve certain quality levels. As Shaked and Sutton (1987, p. 136) suggest, in the case of vertical product differentiation this assumption is "more likely to be valid in those industries in which the main burden of product improvement falls on fixed costs, rather than on variable costs." Finally, we assume that the marginal quality cost efficiencies differ among the firms (see also Zhou, Spencer and Vertinsky 2002, MoragaGonzáles and Viaene 2005, and Kúnin and Žigić 2004). Thus, the DC firms are assumed to have a higher R\&D efficiency or better skilled workers reflecting their lower opportunity costs due to, say, a higher level of human capital. This consequently implies that lower investments are needed in order to achieve a certain quality level.

As already indicated, we are particularly interested in how simple trade policy fares in the given setup vis-à-vis free trade and also how it, in the presence of leadership and imitation, affects the phenomenon of quality reversals (i.e., changes in the ranking of qualities). Thus, we identify conditions under which the optimal trade policy leads to a quality reversal. Our results indicate that the optimal trade policy gives an incentive to the domestic follower to imitate, and quality reversal becomes more likely when imitation is easier. More specifically, we show that quality reversal tends to occur when the difference between the firms' technological levels (measured by marginal efficiencies of firms' investments in qualities) is small, and this result is amplified under the possibility of imitation. In addition, when trade policy leads to quality reversal, and the degree of imitation is not large, it in general, also improves the domestic country's domestic welfare vis-à-vis free trade. On the other hand, when trade policy does not have quality reversal as an outcome, then free trade yields generally a larger domestic welfare. This raises an interesting commitment issue and provides a rationale for the domestic

\footnotetext{
${ }^{4}$ More specifically, we calculate the subgame perfect tariff since subgame perfection implies time consistency but not necessarily vice versa (see Fershtman 1989).
} 
government to commit to free trade. Such a commitment can be achieved, for instance, by a bilateral trade agreement or participation in a trade union.

The remainder of the paper is organized as follows. After a brief literature review in Subsection 1.1, in Section 2, we introduce the model and the underlying assumptions. In Sections 3 and 4, we solve for price the competition equilibrium and the optimal tariff. In Section 5, we analyze firms' quality choices. In Section 6, we compare the free trade and the trade policy equilibria and address the welfare effects. Section 7 concludes and discusses our results. Appendix A contains the proofs of lemmas and propositions. Supplementary appendices are available on Eugen Kovac's homepage. ${ }^{5}$

\subsection{Related literature}

Early studies of strategic trade policy focused on markets with either perfectly substitutable or horizontally differentiated products (see Brander 1995 for a survey). In recent years the attention of trade economists has been shifted towards vertically differentiated markets. The idea of vertical differentiation capturing the difference between DCs and LDCs has already been well established in the international trade literature (see Flam and Helpman 1987, Motta, Thisse and Cabrales 1997). However, until recently it has not been used to analyze the effects of trade policies. One of the first theoretical studies analyzing strategic trade policies in the vertically differentiated markets is Ghosh and Das (2001). The authors compare competition in the LDC market, DC market, and a third country market, using a two-stage game. In the first stage, the countries set their trade policies in the form of export taxes (or subsides) and import tariffs. In the second stage, the firms compete in prices. The authors assume that the qualities of the products are given exogenously. They show that in the policy equilibrium, the LDC firm may not be able to survive in the DC market whereas the DC firm always maintains a market share in the LDC market.

Zhou, Spencer and Vertinsky (2000, 2002) introduce endogenous choices of qualities. They capture the difference between the DC firm and the LDC firm by different costs of innovation (investment in quality) and assume that the firms compete in a third country market. To model the endogenous

\footnotetext{
${ }^{5}$ See www.uni-bonn.de/ kovac/papers/it.
} 
choices of qualities, the authors construct a three-stage game adding a middle stage, at which the firms decide on their qualities. As opposed to Ghosh and Das (2001), the policy instruments available to the countries (DC and LDC) are taxes and subsidies on the investment in quality. The authors show that a unilateral policy involves investment tax by the DC and investment subsidy by the LDC. On the other hand, a jointly optimal policy involves the reverse, in order to soften the price competition.

Herguera, Kujal and Petrakis (2002) are the first who analyze the phenomenon of quality reversal. Much like Zhou, Spencer and Vertinsky (2002), they consider a model with endogenous choice of quality but in a domestic market setup, where the competition takes place in one of the firms' home market. The authors analyze policy instruments in the form of ex-ante and ex-post tariffs depending on whether the trade policy is chosen before or after firms' quality decisions. Herguera et al. (2002) do not distinguish between DC and LDC firms and consider the firms (one of them being domestic and the other foreign) to be symmetric in terms of both production technology and marginal efficiency in generating quality. They show that by virtue of ex-post tariffs, the domestic firm always produces the high-quality good implying that the setup in which the foreign firm produces a high quality variety of the good in free trade is not anymore an equilibrium once an optimal (expost) trade policy is applied. In addition, the authors show that the optimal ex-ante tariff is prohibitive resulting in a domestic monopoly whenever the domestic firm produces a lower quality. ${ }^{6}$

Moraga-Gonzáles and Viaene (2005) use a similar setup as Ghosh and Das (2001) but consider endogenous choices of qualities. They also introduce firms' asymmetry stemming from different costs in generating quality in order to describe domestic markets in transition countries. Moraga-Gonzáles and Viaene (2005) provide a rationale for government to induce quality reversal and identify conditions under which it occurs. Kúnin and Žigić (2004) use similar assumptions concerning the difference of DC and LD firms in generating quality as in Zhou et al. (2002) and Moraga-Gonzáles and Viaene

\footnotetext{
${ }^{6}$ The above results hold for Bertrand competition. Both Zhou et al. (2002) and Herguera et al. (2002) also analyze Cournot competition. Since the price competition seems to be a more natural mode of competition in our setup, we do not consider a Cournot-type competition.
} 
(2005), and a related domestic market ex-post tariff setup as in Herguera et al. (2002). However, unlike the rest of the reviewed literature, they focus on the case of a natural duopoly (following the terminology by Shaked and Sutton 1983). In this case, the market is covered in equilibrium and cannot accommodate more than two firms. The authors find under which conditions the optimal trade policy leads to the quality reversal provided the domestic firm is from a LDC. In particular, their results indicate that quality reversals tend to be less likely than previously thought.

\section{Model}

We start with a theoretical model of international trade in vertically differentiated products, where firms from an LDC and DC country compete in both qualities and prices in the LDC domestic market. We consider a single good produced by one foreign DC firm and one domestic LDC firm. The foreign firm (Firm 1) is assumed to be a leader in quality and the domestic firm (Firm 2) a follower. We describe the whole situation as a four-stage game:

1. Firm 1 (the leader) decides whether to be active in the market and chooses its quality (by incurring sunk costs).

2. Firm 2 (the follower) decides whether to be active in the market and chooses its quality (by incurring sunk costs).

3. Domestic government decides on its trade policy.

4. Firms 1 and 2 compete in prices.

We consider two regimes: the trade policy (TP) regime represented by the import tariffs and the free trade (FT) regime. Actually, one can think about stage zero of the above game in which the LDC government decides which regime to choose. That is, whether to initiate a program of strategic trade policy or to commit itself to free trade. However, there is usually a time lag between the announcement and the implementation of strategic trade policies (see for instance, Karp and Perloff 1995, Neary and O'Sullivan 1999, Grossman and Maggi 1998, Neary and Leahy 2000, Ionaşcu and Žigić 2005a). As a consequence, the government may be forced to select the concrete level 
of its policy instrument only after the strategic choice of domestic firms has taken place. Even without an explicit announcement of the policy, the inability of the government to commit to the level of the policy instrument prior to the strategic decision of the firms would result in the same game structure and timing. As Bhattacharjea (1995, p. 291) has noted in the context of an LDC ".... it is historically appropriate to consider a scenario where the home market is initially monopolized by a foreign firm, and a domestic firm enters if it expects to cover its entry costs under the strategic tariff which would be rational for the government to impose after entry."

Thus, our policy instrument is an ex-post tariff, where the tariffs are imposed after the firms' quality choices have been observed. ${ }^{7}$ On the other hand, in the free trade regime, the domestic government does not behave strategically and takes no action in the third stage (corresponding to zero tariffs). Such behavior may be induced by bilateral agreements or the country's membership in a trade organization (see also the welfare analysis in Section 6). In order to solve the model for the time consistent tariff and optimal quality levels, we look for the subgame perfect equilibrium in pure strategies and apply the standard backwards induction concept.

We capture the difference between DC and LDC firms by an asymmetry in their cost structures and the sequential nature of their quality choices and investments. The costs incurred to achieve a certain quality level may be interpreted as $R \& D$ costs or investments into technology, which are sunk in later stages. Under the free trade regime, the sequential structure gives Firm 1 the first-mover advantage, when both firms have the same cost structure. ${ }^{8}$ Moreover, the LDC firm may have cost disadvantages meaning that its opportunity cost to achieve a certain quality level may be higher than for the DC firm. The reason for postulating the differences in the quality cost efficiency stems from different abilities of the firms from the LDC (compared with DC) to elevate the quality levels of its products. Denote $s_{1}$ the quality of Firm 1's product and $s_{2}$ the quality of Firm 2's product. We say that quality reversal occurs when the leader produces a higher quality in the free

\footnotetext{
${ }^{7}$ Alternative instruments to consider could be production subsidies, investment subsidies, anti-dumping measures, or ex-ante tariffs (chosen before firms' qualities). We leave a detailed analysis of these instruments for future research.

${ }^{8}$ Aoki and Prusa (1997) and Lehmann-Grube (1997) show this result in the framework equivalent to the free trade regime without imitation.
} 
trade regime equilibrium (i.e., $s_{1}>s_{2}$ ) whereas it produces a lower quality in the strategic trade policy regime equilibrium (i.e., $\left.s_{2}>s_{1}\right){ }^{9}$

\subsection{Assumptions of the model}

We use the classical model of vertical differentiation, with each consumer being characterized by a parameter $\theta$ and having the following utility function:

$$
U_{\theta}= \begin{cases}\theta s-p, & \text { if he buys good with quality } s \text { for price } p \\ 0, & \text { if he does not buy. }\end{cases}
$$

The parameter $\theta$ can be interpreted as a consumer's appreciation of quality or taste for quality, meaning that the consumer is willing to pay $\theta$ for an increase in quality by one unit. We assume that $\theta$ is uniformly distributed over the interval $[0,1]$.

Remark 1 . Since the taste for quality is not a directly observable economic variable, a more realistic approach could be to characterize the consumers according to their income, as in Shaked and Sutton (1982). However, Tirole (1992, pp. 96-97) shows that these two approaches are equivalent, where $1 / \theta$ can be interpreted as marginal rate of substitution between quality and income. For consumers with a higher income the marginal rate is lower, i.e., $\theta$ is higher.

Remark 2. In order to study the effect of changing the income level in the domestic country, it would be reasonable to consider the consumers uniformly distributed over $[0, \bar{\theta}]$. Although we consider explicitly only the case $\bar{\theta}=1$, the model can easily be adjusted to incorporate the more general setting with arbitrary $\bar{\theta}$. Indeed, as we will argue later (Remark 4), the results remain the same when the parameters are properly adjusted. In addition, note that for any positive price, the consumer with $\theta=0$ prefers not to buy the good. Hence, not all consumers will be served in equilibrium; in other words, the market will be undercovered. In order to obtain a covered

\footnotetext{
${ }^{9}$ Our definition of quality reversal resembles Herguera et al. (2002) and Kúnin and Žigić (2004). On the other hand, Moraga-Gonzáles and Viaene (2005) use a slightly different definition. They obtain multiple equilibria and select one of them using risk-dominance criterion. The authors claim that quality reversal occurs, when the domestic (less efficient) firm becomes the high-quality producer in the unique (risk-dominant) equilibrium of the export game.
} 
market in equilibrium, it is necessary to "narrow" the market by considering a distribution with support $[\underline{\theta}, \bar{\theta}]$, where $\underline{\theta}>0$. This, however, significantly extends and complicates the analysis. Readers interested in the analysis of such markets are referred to Kúnin and Žigić (2004) for a treatment of the simultaneous quality choice model without imitation.

Based on the qualities (denoted $s_{1}$ and $s_{2}$ ) and prices (denoted $p_{1}$ and $p_{2}$ ) offered by Firms 1 and 2, the consumers choose between buying the product from Firm 1 or from Firm 2, or not buying at all. This choice then determines firms' demands $D_{1}$ and $D_{2}$. We assume that the production is costless, but R\&D yielding a particular product quality may involve certain fixed costs (incurred in stages 1 and 2 and sunk later). Therefore, the firms' gross profits are

$$
\Pi_{1}=\left(p_{1}-t\right) D_{1}, \quad \Pi_{2}=p_{2} D_{2},
$$

where $t$ is the tariff imposed on the foreign firm's imports. The value of $t$ is chosen by the domestic government in stage 3. The gross profit (sometimes we will refer to is as just profit) does not take into account fixed costs. The fixed costs of R\&D are sunk and hence do not influence firms' behavior in the last stage. The profit obtained from gross profit after subtracting the fixed costs will be referred to as net profit.

As mentioned above, in the free trade (FT) regime, the domestic (LDC) government takes no action, so corresponding import tariffs are equal to zero. On the other hand, under the trade policy (TP) regime, the domestic government decides on its trade policy by setting the optimal level of the import tariff in order to maximize the domestic welfare. The domestic welfare $(D W)$ is defined as the sum of the consumer surplus $(C S)$, income from tariffs net of subsidies $T$, and the domestic firm's gross profit $\left(\Pi_{2}\right)$ decreased by its fixed costs $\left(C_{2}\right)$. Formally,

$$
D W=C S+T+\Pi_{2}-C_{2} .
$$

In stages 1 and 2, Firm 1 and Firm 2 choose their qualities in order to maximize their net profit. The net profit is defined as the difference between the gross profit and a firm's fixed costs necessary to develop a certain quality. 
Firm 2's choice of quality in stage 2 is affected by the possibility of imitation since it allows it to obtain certain quality level with lower costs (i.e., without incurring the full costs of R\&D).

The possibility of imitation has not been properly explored in the industrial organization literature, within the vertical differentiation model. As an exception Pepall (1997) considers a model with two firms: one being a leader in quality, the other a follower. In her approach, the leader chooses its quality (say $s_{1}$ ) by incurring a given, exogenously set level of sunk costs $K$, whereas the follower's costs (of choosing quality $s_{2}$ ) are due to imitation only a fraction of it and have the form $K\left(s_{1}-s_{2}\right)^{2}$. There are two important features of this cost structure which we consider not relevant in international trade and in which our specification differs from Pepall (1997). First, the leader's quality costs in her approach are fixed and do not depend on quality $s_{1}$. Second, the follower's quality costs are decreasing on interval $\left[0, s_{1}\right]$. As a consequence, the costs of achieving zero quality are paradoxically the largest (on that interval). As Pepall (1997, p. 267) suggests, $K$ represents the costs incurred "to market a new product". In this sense the model may be appropriate to describe, for example, marketing ideas, where the follower's costs would be indeed close to zero when it copies, say, the same design. However, when quality is interpreted as reflecting the level of technology, we find Pepall's specification inappropriate. Even if fixed costs are interpreted as costs of R\&D in order to achieve some invention, high costs may be necessary in order to copy the same invention, but lower costs to make an inferior copy of the invention. For example, it may be difficult to copy the recent technological inventions, but easy to copy older inventions of "lower quality" (e.g., slower microchips).

We assume that Firm 1 (leader) has the following cost function:

$$
C_{1}\left(s_{1}\right)=\frac{1}{2} \gamma_{1} s_{1}^{2}
$$

where $\gamma_{1}>0$ is a positive parameter and reflects, for example, the efficiency of investments (like investments in $R \& D$ ). A lower value of $\gamma_{1}$ means that investments are more efficient, in the sense that the costs of achieving a certain quality level are lower. Under the above cost function, Firm 1's marginal costs (with respect to quality) are $C_{1}^{\prime}\left(s_{1}\right)=\gamma_{1} s_{1}$. 
On the other hand, Firm 2's cost function is more complex since it should reflect both a lower degree of the country's economic development and the possibility of imitation. In particular, we impose the following conditions:

(i) Without imitation, Firm 2's costs have the same form, with a lower efficiency of investments, represented by parameter $\gamma_{2}$, where $\gamma_{2} \geq \gamma_{1}$.

(ii) Due to imitation, Firm 2's marginal costs decrease proportionally when it produces a lower quality good. Let $1-\mu$ be the proportion, where $\mu \in[0,1]$.

(iii) Imitation does not alter Firm 2's marginal costs when it produces a higher quality good (i.e., costs of quality improvement by an additional unit are unchanged).

(iv) Firm 2's cost function is continuous.

Under these conditions, Firm 2's cost function can be written as (see Appendix A for details)

$$
C_{2}\left(s_{1}, s_{2}\right)= \begin{cases}\frac{1}{2} \gamma_{2}(1-\mu) s_{2}^{2}, & \text { if } s_{2} \leq s_{1} \\ \frac{1}{2} \gamma_{2}\left(s_{2}^{2}-\mu s_{1}^{2}\right), & \text { if } s_{2}>s_{1}\end{cases}
$$

Firm 2's marginal costs then are

$$
\frac{\partial}{\partial s_{2}} C_{2}\left(s_{1}, s_{2}\right)= \begin{cases}\gamma_{2}(1-\mu) s_{2}, & \text { if } s_{2} \leq s_{1} \\ \gamma_{2} s_{2}, & \text { if } s_{2}>s_{1}\end{cases}
$$

The parameter $\gamma_{2}$ similarly corresponds to Firm 2's investment efficiency and the parameter $\mu$ represents the degree of imitation. The inequality $\gamma_{1} \leq \gamma_{2}$ reflects the fact that without imitation the LDC firm needs to incur higher (or equal) costs than the DC firm in order to achieve certain same quality level. We assume that $1-\mu \leq 1$, since imitation decreases Firm 2's costs. In particular, when $\mu=0$, then there is no imitation. If, in addition, $\gamma_{2}=\gamma_{1}$, then Firm 2's cost function is the same as the Firm 1's one. On the other hand, the case $\mu=1$ corresponds to full imitation, i.e., Firm 2 may replicate any quality $s_{2} \leq s_{1}$ with no costs. In general, the higher the value of $\mu$, 
the easier imitation is. Alternatively, $\mu$ can be interpreted as intensity of imitation, the size of spillovers, or the degree of intellectual property rights (IPR) violation. It is worthwhile to note that although Firm 2's cost function is continuous, its marginal costs are not. In particular, $C_{2}\left(s_{1}, s_{2}\right)$ has a kink when $s_{2}=s_{1}$. Note also that the conditions (i)-(iv) can be easily adjusted when the Firm 1's cost function has a different form.

\section{Price competition in the last stage}

Proceeding backwards, we start with the price competition in the last stage. In this respect, we need to analyze two cases depending on the ranking of qualities. First, we analyze the case where Firm 2 (the domestic LDC firm) produces a lower quality, i.e., $s_{1}>s_{2}$. When Firms 1 and 2 offer their products for prices $p_{1}$ and $p_{2}$, they face the following demands:

$$
D_{1}=1-\theta_{12}, \quad D_{2}=\theta_{12}-\theta_{20}, \quad \text { where } \quad \theta_{12}=\frac{p_{1}-p_{2}}{s_{1}-s_{2}}, \quad \theta_{20}=\frac{p_{2}}{s_{2}}
$$

denote the consumer who is indifferent between buying the good from Firms 1 and 2, and the consumer who is indifferent between buying the good from Firm 2 and not buying at all, respectively.

The equilibrium in the last stage is given by a maximization of firms' profits (1). It can be easily computed that:

$$
p_{1}^{*}=\frac{2 s_{1}\left(s_{1}-s_{2}+t\right)}{4 s_{1}-s_{2}}, \quad p_{2}^{*}=\frac{s_{2}\left(s_{1}-s_{2}+t\right)}{4 s_{1}-s_{2}} .
$$

This yields the indifferent consumers

$$
\theta_{12}^{*}=\frac{\left(2 s_{1}-s_{2}\right)\left(s_{1}-s_{2}+t\right)}{\left(s_{1}-s_{2}\right)\left(4 s_{1}-s_{2}\right)}, \quad \theta_{20}^{*}=\frac{s_{1}-s_{2}+t}{4 s_{1}-s_{2}}
$$

and the firms' equilibrium profits

$$
\Pi_{1}^{*}=\frac{\left[2 s_{1}\left(s_{1}-s_{2}\right)-\left(2 s_{1}-s_{2}\right) t\right]^{2}}{\left(s_{1}-s_{2}\right)\left(4 s_{1}-s_{2}\right)^{2}}, \quad \Pi_{2}^{*}=\frac{s_{1} s_{2}\left(s_{1}-s_{2}+t\right)^{2}}{\left(s_{1}-s_{2}\right)\left(4 s_{1}-s_{2}\right)^{2}}
$$

It is worthwhile to note that in this setup, tariff does not a have direct impact on relative prices, since $p_{2} / p_{1}=s_{2} /\left(2 s_{1}\right)=s / 2$. The quality ratio 
$s=s_{2} / s_{1}<1$ measures the toughness of competition. When $s \in(0,1)$, an increase in $s$ intensifies price competition leading to the Bertrand paradox in the limiting case when $s=1$. Therefore, there is an important indirect effect of trade policy since, as we will see, the anticipation of tariffs does affect the equilibrium choice of qualities, $s_{1}$ and $s_{2}$, and hence quality ratio $s$.

In order for prices (6) to form an equilibrium, it is necessary that the inequalities $0 \leq \theta_{20}^{*} \leq \theta_{12}^{*} \leq 1$ hold. The inequality $\theta_{12}^{*} \leq 1$ holds, if and only if $t \leq 2 s_{1}\left(s_{1}-s_{2}\right) /\left(2 s_{1}-s_{2}\right)$, implying that the optimal tariff has to be lower than $s_{1}$. If the last condition does not hold, the tariff is so high that the Firm 1's market share cannot be positive. In this case, Firm 2 is the only one in the market, and the only viable market structure is domestic monopoly (see Remark 3). On the other hand, if the last condition holds with equality, Firm 1's gross profit is exactly zero resulting (in the absence of fixed costs) in the market structure called constrained domestic monopoly. That is, Firm 1 is indifferent between being active and not active in the market, but its presence still influences Firm 2's decision. The inequalities $0 \leq \theta_{20}^{*}$ and $\theta_{20}^{*} \leq \theta_{12}^{*}$ are equivalent and hold, if and only if $t \geq-\left(s_{1}-s_{2}\right)$. This is obviously satisfied when the tariff is non-negative. On the other hand, the domestic country may decide to subsidize imports because of the low quality of the domestic firm's good. When the subsidies are so high that the last inequality does not hold, the resulting market structure is foreign monopoly. Remark 3 . In the case of a monopoly, the monopolist firm with quality $s_{M}$ maximizes its profit $\Pi_{M}=p_{M}\left(1-p_{M} / s_{M}\right)$, yielding the optimal price $p_{M}^{*}=$ $s_{M} / 2$ and profit $\Pi_{M}^{*}=s_{M} / 4$. The domestic welfare (see below) is $3 s_{M} / 8$, in the case of a domestic monopoly, and $\left(s_{M}-t\right)\left(s_{M}+3 t\right) /\left(8 s_{M}\right)$ in the case of a foreign monopoly when tariff $t$ is imposed.

The explicit solution of the price competition equilibrium also offers interesting insights about comparative statics with respect to the import tariff $t$. One can easily see that both firms' equilibrium prices are increasing in $t$. Intuitively, Firm 1's price is higher since it compensates for losses caused by a higher tariff. Due to strategic complementarity, Firm 2 is also willing to raise its price, leading to equilibrium with higher prices. On the other hand, note that Firm 1's price net of tariff, that is $p_{1}-t$, is decreasing in $t$, which reflects the standard impact of tariffs to improve the terms of trade of the 
domestic country. Due to higher prices, the measure of consumers served in equilibrium (that is, the size of the market, which is $1-\theta_{20}$ ) is decreasing in $t$. Despite this, the domestic firm (Firm 2) faces an increase in its demand (equal to $\theta_{12}-\theta_{20}$ ), provided the tariff leads to duopoly (i.e., it satisfies the above conditions).

The straightforward consequences of this is that Firm 1's profit is decreasing in $t$, whereas Firm 2's profit is increasing in $t$; see also the expressions for equilibrium profits (7). This is in line with the basic idea of strategic tariffs: shifting the profits from the foreign firm to the domestic firm.

Analogically we may proceed in the case where Firm 2 produces a higher quality, i.e., $s_{2}>s_{1}$. In this case the firms' demands are:

$$
D_{2}=1-\theta_{21}, \quad D_{1}=\theta_{21}-\theta_{10}, \quad \text { where } \quad \theta_{21}=\frac{p_{2}-p_{1}}{s_{2}-s_{1}}, \quad \theta_{10}=\frac{p_{1}}{s_{1}}
$$

denote the consumer who is indifferent between buying the good from Firms 2 and 1 , and the consumer who is indifferent between buying the good from Firm 1 and not buying at all, respectively. The equilibrium in the last stage is given by a maximization of the profits (1), and it can be easily computed that:

$$
p_{2}^{*}=\frac{s_{2}\left(2 s_{2}-2 s_{1}+t\right)}{4 s_{2}-s_{1}}, \quad p_{1}^{*}=\frac{2 s_{2} t+s_{1} s_{2}-s_{1}^{2}}{4 s_{2}-s_{1}} .
$$

This yields the indifferent consumers

$$
\theta_{21}^{*}=\frac{\left(s_{2}-s_{1}\right)\left(2 s_{2}-s_{1}\right)-s_{2} t}{\left(s_{2}-s_{1}\right)\left(4 s_{2}-s_{1}\right)}, \quad \theta_{10}^{*}=\frac{s_{1}\left(s_{2}-s_{1}\right)+2 s_{2} t}{s_{1}\left(4 s_{2}-s_{1}\right)}
$$

and the firms' equilibrium profits

$$
\Pi_{2}^{*}=\frac{s_{2}^{2}\left(2 s_{2}-2 s_{1}+t\right)^{2}}{\left(s_{2}-s_{1}\right)\left(4 s_{2}-s_{1}\right)^{2}}, \quad \Pi_{1}^{*}=\frac{s_{2}\left[s_{1}\left(s_{2}-s_{1}\right)-\left(2 s_{2}-s_{1}\right) t\right]^{2}}{s_{1}\left(s_{2}-s_{1}\right)\left(4 s_{2}-s_{1}\right)^{2}} .
$$

Much like before, in order for the above to be an equilibrium, it is necessary that the inequalities $0 \leq \theta_{10}^{*} \leq \theta_{21}^{*} \leq 1$ hold. We will not elaborate upon these conditions further since it would not provide any additional insights. However, later we check that they are satisfied by the optimal tariff.

Again, with an explicit solution of the price competition equilibrium, we are able to derive insights about comparative statics with respect to the 
import tariff $t$. One can easily observe that the effect of tariff on equilibrium prices, firms' demands, and firms' profits is the same as in the previous case. In particular, we point out that Firm 1's profit is decreasing in $t$, whereas Firm 2's profit is increasing in $t$.

\section{Tariff choice}

In the free trade (FT) regime, the domestic government takes no action in the third stage, which may be represented by tariff $t=0$. The corresponding price competition equilibrium can then be obtained from (6), (7) when $s_{2}<$ $s_{1}$, and from (8), (9) when $s_{2}>s_{1}$, by setting $t=0$. Firms' continuation profits (equilibrium profits from subsequent stages) are shown in Table 1 in Appendix B.

On the other hand, under the trade policy (TP) regime, the domestic government decides on its trade policy by maximizing the domestic welfare given by (2). If the LDC firm (Firm 2) produces a lower quality, then the domestic welfare (in duopoly) can be rewritten as follows:

$$
\begin{aligned}
D W & =\underbrace{\int_{\theta_{20}}^{\theta_{12}}\left(\theta s_{2}-p_{2}\right) \mathrm{d} \theta+\int_{\theta_{12}}^{1}\left(\theta s_{1}-p_{1}\right) \mathrm{d} \theta}_{C S}+\underbrace{t\left(1-\theta_{12}\right)}_{T}+\underbrace{p_{2}\left(\theta_{12}-\theta_{20}\right)}_{\Pi_{2}}-C_{2}= \\
& =s_{2} \int_{\theta_{20}}^{\theta_{12}} \theta \mathrm{d} \theta+s_{1} \int_{\theta_{12}}^{1} \theta \mathrm{d} \theta-\Pi_{1}-C_{2} .
\end{aligned}
$$

When choosing the tariff, the domestic government anticipates the price competition equilibrium in the last stage. Note, however, that Firm 2's fixed cost $C_{2}$ is sunk at this stage. Thus, it does not influence the domestic government's maximization problem, and it may be treated as a constant. In the equilibrium with prices given by (6), the equilibrium domestic welfare is

$$
D W^{*}=\frac{s_{1}\left(s_{1}-s_{2}\right)\left(s_{1}+2 s_{2}+2 t\right)-\left(3 s_{1}-2 s_{2}\right) t^{2}}{2\left(4 s_{1}-s_{2}\right)\left(s_{1}-s_{2}\right)}-C_{2} .
$$

Obviously, the domestic welfare is concave in tariffs and attains its maximum for

$$
t^{*}=\frac{s_{1}\left(s_{1}-s_{2}\right)}{3 s_{1}-2 s_{2}},
$$


which consequently represents the tariff chosen by the domestic country in the subgame perfect equilibrium. It can be easily shown that under this tariff, duopoly is the equilibrium market structure (i.e., inequalities $0 \leq$ $\theta_{20}^{*} \leq \theta_{12}^{*} \leq 1$ hold). In addition, comparison of the welfare for tariff $t^{*}$ with welfare under other market structures (namely, domestic and foreign monopoly, as discussed in Remark 3) shows that duopoly is the equilibrium market structure, and tariff $t^{*}$ is optimal.

Note that the optimal tariff is increasing in $s_{1}$ and decreasing in $s_{2} \cdot{ }^{10}$ Moreover, the optimal tariff is always positive. Thus, in the absence of a credible commitment mechanism, the domestic LDC country never prefers ex-post (after the qualities have been chosen) trade policy over free trade. Consequently, Firm 1's profit is lower and Firm 2's profit is higher than their respective profits in the free trade equilibrium, when $t=0$ (according to the comparative statics results from the previous section). The price competition equilibrium resulting from this tariff can be then obtained from (6) and (7); see Table 1.

If the LDC firm produces a higher quality, by the same procedure as in the previous case, we obtain $D W=s_{1} \int_{\theta_{10}}^{\theta_{21}} \theta \mathrm{d} \theta+s_{2} \int_{\theta_{21}}^{1} \theta \mathrm{d} \theta-\Pi_{1}-C_{2}$, and in equilibrium

$$
D W^{*}=\frac{s_{2} s_{1}\left(s_{2}-s_{1}\right)\left(3 s_{2}+2 t\right)-\left(3 s_{2}-2 s_{1}\right) t^{2}}{2\left(4 s_{2}-s_{1}\right)\left(s_{2}-s_{1}\right)}-C_{2} .
$$

Again, the domestic welfare is concave in tariffs and attains its maximum for

$$
t^{*}=\frac{s_{1}\left(s_{2}-s_{1}\right)}{3 s_{2}-2 s_{1}}
$$

It can be easily shown that for such a tariff, duopoly is the equilibrium market structure (i.e., inequalities $0 \leq \theta_{10}^{*} \leq \theta_{21}^{*} \leq 1$ hold). ${ }^{11}$ Again, a comparison of the welfare for tariff $t^{*}$ with the welfare under other domestic and foreign monopoly shows that duopoly is the equilibrium market structure, and tariff $t^{*}$ is optimal.

\footnotetext{
${ }^{10}$ This may be obtained by taking derivatives $\mathrm{d} t^{*} / \mathrm{d} s_{1}=\left[2\left(s_{1}-s_{2}\right)^{2}+s_{1}^{2}\right] /\left(3 s_{1}-2 s_{2}\right)^{2}>$ 0, and $\mathrm{d} t^{*} / \mathrm{d} s_{2}=-s_{1}^{2} /\left(3 s_{1}-2 s_{2}\right)^{2}<0$.

${ }^{11}$ Note that $\theta_{10}^{*} \leq \theta_{21}^{*}$ holds, if and only if $t^{*} \leq s_{1}\left(s_{2}-s_{1}\right) /\left(2 s_{2}-s_{1}\right)$, or equivalently $s_{1} \leq s_{2}$.
} 
Likewise as in the previous case, the optimal tariff is positive and again without a possibility of credible commitment, the domestic country prefers ex-post trade policy over free trade. Moreover, by the same argument sa above, Firm 1's profit is lower and Firm 2's profit is higher than their respective profits in the free trade equilibrium.

Table 1 summarizes the results and shows firms' continuation profits. Note that the profits are continuous (and equal to zero) when $s_{1}=s_{2}$. In further analysis, we shall use only those continuation profits, and hence, we omit the stars denoting equilibrium. Moreover, since most of the results hold generally for both regimes, we shall use in most cases a general notation, without specifying the regime. Sometimes, when convenient, we add superscript FT for the free trade regime and superscript TP for the trade policy regime.

\section{Quality choices}

In the previous sections, we have found the equilibrium of the price competition in the last stage and corresponding optimal tariffs chosen by the domestic country in the third stage. In this section, we analyze the choice of qualities in the first and second stage. Having established the equilibrium in later stages, it is sufficient to analyze a reduced form of the whole game with payoffs represented by continuation profits from Table 1. We will refer to this reduced game as the quality choice game.

Before we start with the formal analysis, for the ease of exposition, we shall introduce a new notation. In particular, we now use explicitly the variable $s$ (quality ratio) and we introduce a new variable $q$, which are defined as

$$
s=\frac{s_{2}}{s_{1}}, \quad q=\gamma_{2} s_{1} .
$$

In addition, we denote

$$
\begin{array}{rlrl}
\alpha & =\gamma_{1} / \gamma_{2}, & \pi_{i}(s)=\Pi_{i}(1, s), \quad i=1,2 \\
c_{1}=C_{1}(1) / \gamma_{2}=\frac{1}{2} \alpha, & c_{2}(s)=C_{2}(1, s) / \gamma_{2} .
\end{array}
$$

The new parameter $\alpha$ represents the relative efficiency (or technological gap) 
of Firm 2 compared to Firm 1. According to the above assumptions, we have $0<\alpha \leq 1$. The value $\alpha=1$ implies that (without imitation) the firms are symmetric as to the cost structure. On the other hand, values of $\alpha$ close to zero mean that Firm 1's production is almost costless compared to Firm 2, i.e., Firm 2 is completely inefficient compared to Firm 1.

Since all profits in Table 1 are homogeneous of degree 1, and all cost functions are homogeneous of degree 2 in $\left(s_{1}, s_{2}\right)$, then

$$
\begin{aligned}
& \Pi_{i}\left(s_{1}, s_{2}\right)=s_{1} \Pi_{i}(1, s)=q \pi_{i}(s) / \gamma_{2}, \\
& C_{1}\left(s_{1}\right)=\frac{1}{2} \alpha q^{2} / \gamma_{2}, \quad C_{2}\left(s_{1}, s_{2}\right)=s_{1}^{2} C_{2}(1, s)=q^{2} c_{2}(s) / \gamma_{2} \text {. }
\end{aligned}
$$

Due to the sequential structure of decisions and the fact that $q$ does not depend on $s_{2}$, we may consider $q$ as Firm 1's decision variable and $s$ as Firm 2 's decision variable, with interval $[0, \infty)$ as the set of available strategies for both firms. The introduction of $q$ and $\alpha$ reduces the parameter space by one dimension. Instead of $\gamma_{1}, \gamma_{2}$, and $\mu$, all strategic decisions (i.e., firms' equilibrium choices of $q$ and $s$ ) will depend only on $\alpha$ and $\mu$. Therefore, in order to simplify further analysis, we will without loss of generality use the normalization

$$
\gamma_{2}=1
$$

Remark 4. As mentioned earlier (Remark 2), the model can be easily adjusted to consider consumers uniformly distributed on interval $[0, \bar{\theta}]$. Indeed, if we normalize the new variables $\pi_{1}, \pi_{2}$, and $q$ by factor $1 / \bar{\theta}$ (e.g., we define $\left.q=\gamma_{2} s_{1} / \bar{\theta}\right)$, the results obtained in the following chapters do not change.

\subsection{Follower's maximization problem}

In the second stage, the follower (Firm 2) maximizes its net profit anticipating the price competition equilibrium and domestic government's tariff choice. The net profit is the difference between firm's gross profit (revenue) and costs of achieving certain a quality, i.e., $\Pi_{2}\left(s_{1}, s_{2}\right)-C_{2}\left(s_{1}, s_{2}\right)$. Under the new notation, the follower's maximization problem is equivalent to:

$$
\max _{s} \pi_{2}(s)-q c_{2}(s)
$$


The exact expressions for $\pi_{2}(s)$ and $c_{2}(s)$ can be found in Table 2 in Appendix B. Note that both $\pi_{2}(s)$ and $c_{2}(s)$ are continuous, but have a kink in $s=1$. Moreover, both have a continuous second derivative (are $\mathcal{C}^{2}$ ) on both intervals $[0,1)$ and $(1, \infty)$. Therefore, Firm 2's net profit function can, in principle, attain the maximum in any of the following cases:

(a) $s=0$;

(b) $s \in(0,1)$ satisfying the first-order conditions;

(c) $s=1$;

(d) $s \in(1, \infty)$ satisfying the first-order conditions; and

(e) there is no maximum (net profit is not bounded from above).

Note that cases (a) and (e) correspond to a maximal product differentiation, and case (c) corresponds to a minimal product differentiation. In case (a), Firm 2's net profit is zero, whereas in case (c) it is negative (gross profit is zero, but costs are positive). Moreover, it can be also easily established that $\pi_{2}(s)-q c_{2}(s) \rightarrow-\infty$ (for any $q>0$ ) as $s \rightarrow \infty$ (since the costs are of "higher order" than profits). Therefore, we may exclude cases (c) and (e) as candidates for maximum. The first-order conditions for an interior solution, i.e., in cases (b) and (d), can be written as

$$
\pi_{2}^{\prime}(s)=q c_{2}^{\prime}(s)
$$

The expressions for the first derivative of Firm 2's gross profit can be found in Table 3 in Appendix B, and are illustrated in Figure 1 in Appendix B. The solid line represents the derivative in the FT regime, and the dashed line represents the rerivative in the TP regime (see Table 3 for particular values). The figure shows that in both regimes, the derivative is decreasing on interval $[0,1]$ and on interval $[1, \infty)$, with a jump upwards at $s=1$. Hence, Firm 2 's gross profit is concave on these intervals, in both regimes. This can be obtained also by verifying that $\pi_{2}^{\prime \prime}(s)<0$ for all $s>0$. Moreover, observe that $c_{2}^{\prime}(0)=0$, which implies $\pi_{2}^{\prime}(0)-q c_{2}^{\prime}(0)=\pi_{2}^{\prime}(0)>0$. Therefore, Firm 2 's net profit is increasing and hence positive when $s$ is close to zero. Thus, we may also exclude case (a). 
Now we know that Firm 2's net profit attains its maximum either in case (b) or (d), i.e., the first-order condition (16) is satisfied. Its solution is given by the intersection of $\pi_{2}^{\prime}(s)$ with the line $q(1-\mu) s$ when $s<1$, and with the line $q s$ when $s>1$ (see Figure 2 in Appendix B for illustration). Note that this solution depends on Firm 1's decision $q$ only through the slope of this line. Moreover, Firm 2's optimization problem (15), and hence its solution too, does not depend on $\alpha$. Thus, all results presented in this section hold uniformly for all $\alpha \in(0,1]$. The following lemmas provide some basic results (see Appendix A for their proofs).

Lemma 1. For all $q \geq 0$, there exists a unique solution of (16) on interval $(0,1)$.

Lemma 2. There exists a solution of $(16)$ on interval $(1, \infty)$, if and only if $q<\bar{q}$, where $\bar{q}=\frac{4}{9}$ in the free trade regime, and $\bar{q}=1$ in the trade policy regime. ${ }^{12}$ This solution is then unique and does not depend on $\mu$.

Let $s^{1}(q)$ be the solution of the first-order condition (16) on interval $(0,1)$ and $s^{2}(q)$ the solution on interval $(1, \infty)$, if it exists. ${ }^{13}$ Furthermore, denote $s^{*}(q)$ the maximizer of Firm 2's net profit (i.e., its best response). The above analysis and Lemmas 1 and 2 show that $s^{*}(q)=s^{1}(q)$ for $q \geq \bar{q}$, with $\bar{q}$ defined accordingly to the regime. Let us now concentrate on the case, when $q<\bar{q}$.

Lemma 3. Functions $s^{1}(q)$ and $s^{2}(q)$ (when defined) have a continuous first derivative (are $\mathcal{C}^{1}$ ) and are decreasing in $q$.

For any $q \geq 0$ we obtained two candidates, $s^{1}(q)$ and $s^{2}(q)$, for Firm 2's optimal decision. In order to find its best response, we need to compare its net profits from choosing qualities $s^{1}(q)$ and $s^{2}(q)$.

\footnotetext{
${ }^{12}$ Sometimes, when convenient, we add a superscript determining the regime, i.e., $\bar{q}^{\mathrm{FT}}=$ $\frac{4}{9}$ and $\bar{q}^{\mathrm{TP}}=1$.

${ }^{13}$ With superscripts 1 and 2 , we distinguish between the solutions from interval $(0,1)$, where Firm 1 produces a higher quality and from interval $(1, \infty)$, where Firm 2 produces a higher quality. In addition, for the purposes of comparative statics, we will use $\mu$ as subscript, e.g., we write $s_{\mu}^{1}(q)$.
} 
Proposition 1. For any $\mu \in[0,1]$, there exists a threshold $\hat{q} \in(0, \bar{q})$ such that:

$$
s^{*}(q)= \begin{cases}s^{1}(q)<1, & \text { if } q>\hat{q}, \\ s^{2}(q)>1, & \text { if } q<\hat{q} .\end{cases}
$$

Corollary 1. For any $\mu \in[0,1]$, Firm 2's best response $s^{*}(q)$ has the following properties:

(i) $s^{*}(q)$ is continuously differentiable and decreasing on $[0, \hat{q})$ and on $(\hat{q}, \infty)$.

(ii) $s^{*}(q)>1$ on $[0, \hat{q})$ and $s^{*}(q)<1$ on $(\hat{q}, \infty)$.

(iii) $s^{*}(q)$ has a jump downwards at $q=\hat{q}$.

(iv) $s^{*}(q) \rightarrow \infty$ when $q \rightarrow 0^{+}$, and $s^{*}(q) \rightarrow 0$ when $q \rightarrow \infty$.

See Appendix A for proofs and Figure 3 in Appendix B for illustration. According to Proposition 1, Firm 2 chooses a higher quality when $q$ is below the threshold $\hat{q}$ and a lower quality when $q$ is above the threshold. Note that the value of $\hat{q}$ depends only on the degree of imitation $\mu$. However, the values of $\hat{q}$ in the FT regime and the TP regime may be different. ${ }^{14}$

Note that since $s^{*}(q)$ is decreasing in $q$, we have a situation of strategic substitutes. More precisely, Proposition 1 shows that if Firm 1 chooses its quality $s_{1}$ sufficiently low (i.e., $q=\gamma_{2} s_{1}$ is sufficiently low), then Firm 2 chooses a higher quality $s_{2}>s_{1}$ (i.e., $s^{*}(q)>1$ ). If, on the other hand, Firm 1 chooses its quality $s_{1}$ sufficiently high (i.e., $q$ is high), then Firm 2 chooses a lower quality $s_{2}<s_{1}$ (i.e., $s^{*}(q)<1$ ). Intuitively, by choosing a low quality, Firm 1 leaves enough space for Firm 2, which consequently finds it profitable to choose a higher quality. Conversely, when Firm 1 chooses a high quality, Firm 2 will find a higher quality not profitable and will consequently choose a lower quality.

\footnotetext{
${ }^{14}$ Following Footnote 13 we will capture the dependence on $\mu$ using subscript $\mu$ (i.e., $\hat{q}_{\mu}$ ). In addition, we also denote $\hat{q}^{\mathrm{FT}}$ and $\hat{q}^{\mathrm{TP}}$ the values of $\hat{q}$ in the $\mathrm{FT}$ and the TP regimes, respectively.
} 
The particular value of $\hat{q}_{\mu}$ can be found by solving the following system of three equations

$$
\begin{aligned}
\pi_{2}^{\prime}\left(s^{1}\right) & =q c_{2}^{\prime}\left(s^{1}\right), \\
\pi_{2}^{\prime}\left(s^{2}\right) & =q c_{2}^{\prime}\left(s^{2}\right), \\
\pi_{2}\left(s^{1}\right)-q c_{2}\left(s^{1}\right) & =\pi_{2}\left(s^{2}\right)-q c_{2}\left(s^{2}\right),
\end{aligned}
$$

with unknowns $q, s^{1}, s^{2}$, where $s^{1}<1<s^{2}$. The first two equations represent the first-order conditions for $s^{1}<1$ and $s^{2}>1$, respectively. Recall that the expressions for $\pi_{2}(s)$, and also $c_{2}(s)$, are different when $s<1$ and when $s>1$. The third equation represents the equality of net profits, i.e., Firm 2 is indifferent between choosing a higher quality $s^{2}$ and a lower quality $s^{1}$ than Firm 1.

It is not possible to solve the above system explicitly in terms of $\mu$. However, we may still derive certain properties of the solution and for any $\mu \in[0,1]$ we may solve the system numerically. The following propositions provide some comparative statics results with respect to the degree of imitation $\mu$ (see Appendix A for their proofs).

Proposition 2. For any fixed $q$ such that $q \notin\left\{0, \hat{q}_{\mu}\right\}$, the follower's optimal net profit $\pi_{2}\left(s_{\mu}^{*}(q)\right)-q c_{2}\left(s_{\mu}^{*}(q)\right)$ is increasing in the degree of imitation $\mu .^{15}$

Proposition 3. For any fixed $q$, the follower's best response $s_{\mu}^{*}(q)$ is nondecreasing in the degree of imitation $\mu$. In particular:

(i) For any fixed $q, s_{\mu}^{1}$ is increasing in $\mu$.

(ii) For any fixed $q, s_{\mu}^{2}$ does not depend on $\mu$.

(iii) The threshold $\hat{q}_{\mu}$ is increasing in $\mu$.

Proposition 2 suggests that imitation raises the follower's profit. Based on the Envelope Theorem argument, this effect is driven by the reduction of fixed costs due to imitation (see its proof). Proposition 3 suggests that imitation has also a positive effect on the follower's quality when it is lower than the leader's one. On the other hand, imitation has no effect on the

\footnotetext{
${ }^{15}$ Recall that $c_{2}(s)$ depends on $\mu$; see Table 2 for details.
} 
follower's quality choice when it exceeds the leader's quality. This result follows from the fact that imitation does not affect the follower's marginal costs when it chooses a higher quality. Finally, the last part shows that when $\mu$ increases, a larger $q$ is necessary to make Firm 2 indifferent between choosing $s^{1}(q)$ and $s^{2}(q)$. The reason is that $s^{1}(q)$ increases in $\mu$, and so a larger $\hat{q}$ is necessary to make Firm 2 indifferent between choosing a higher and a lower quality. The profile of $\hat{q}_{\mu}$ is depicted in Figure 4 in Appendix B (obtained numerically). The figure also shows that

$$
\hat{q}_{\mu}^{\mathrm{FT}}<\hat{q}_{\mu}^{\mathrm{TP}}, \quad \text { for all } \mu \in[0,1]
$$

Quality reversal occurs when Firm 2 chooses a lower quality in the free trade regime (that is, $q>\hat{q}_{\mu}^{\mathrm{FT}}$ holds), but by virtue of trade policy Firm 1 's optimal choice is pushed to the "lower" quality levels (that is, $q<\hat{q}_{\mu}^{\mathrm{TP}}$ ). Note, however, that $q$ is Firm 1's strategic choice and its equilibrium value may be in general different in the $\mathrm{FT}$ and the $\mathrm{TP}$ regimes. The intuition behind quality reversal lies in the fact that the optimal tariff is increasing in Firm's 1 quality (see Footnote 10), and so anticipating this, the equilibrium strategy of the Firm 1 is to downgrade its quality. Thus optimal quality of Firm 1 in the trade policy regime may fall into the critical region of $q$, (that is, $q<\hat{q}_{\mu}^{\mathrm{TP}}$ ) so that the optimal response for Firm 2 is to jump in the quality ladder. In the following section, we analyze Firm 1's choice of $q$ in both regimes and identify the values of the parameters where quality reversal occurs.

\subsection{Leader's maximization problem}

In this section, we analyze the leader's quality choice in the first stage. Anticipating the follower's best response and equilibrium in further stages, the leader (Firm 1) maximizes its net profit $\Pi_{1}\left(s_{1}, s_{2}\right)-C_{1}\left(s_{1}\right)$, subject to Firm 2 's best response. Using the notation introduced in (12)-(14), Firm 1's maximization is equivalent to

$$
\begin{aligned}
& \max _{q, s} q \pi_{1}(s)-\frac{1}{2} \alpha q^{2} \\
& \text { subject to } s=s^{*}(q),
\end{aligned}
$$


with $s^{*}(q)$ given by (17). ${ }^{16}$ Figure 5 in Appendix B shows an example of Firm 1's (continuation) profit, when anticipating Firm 2's best response. The profit has one point of discontinuity, namely $\hat{q}_{\mu}$ (recall that Firm 2's best response has a jump in $q=\hat{q}_{\mu}$ ) and is continuous on both intervals $\left[0, \hat{q}_{\mu}\right)$ and $\left(\hat{q}_{\mu}, \infty\right)$. Firm 1's optimal choice of $q$ satisfies, therefore, one of the following:

(a) $q=0$, leading to an infinite value of $s\left(\right.$ since $s^{*}(q) \rightarrow \infty$ as $q \rightarrow 0^{+}$);

(b) $q \in\left(0, \hat{q}_{\mu}\right)$ satisfying the first-order conditions and leading to Firm 2's response $s^{*}(q)=s^{2}(q)>1$;

(c) $q=\hat{q}_{\mu}$, with Firm 2 being indifferent between $s^{1}(q)$ and $s^{2}(q)$;

(d) $q \in\left(\hat{q}_{\mu}, \infty\right)$ satisfying the first-order conditions and leading to Firm 2's response $s^{*}(q)=s^{1}(q)<1$; and

(e) there is no maximum (net profit is not bounded from above).

According to the following lemma we may rule out cases (a) and (e); its proof can be found in Appendix A.

Lemma 4. For any $\alpha \in(0,1]$ and $\mu \in[0,1]$, Firm 1's profit $q \pi_{1}\left(s^{*}(q)\right)-\frac{1}{2} \alpha q^{2}$

(i) diverges to $-\infty$, when $q \rightarrow \infty$,

(ii) converges to 0 , when $q \rightarrow 0^{+}$, and

(iii) is increasing in $q$, when $q$ is sufficiently small.

In general, each of the remaining cases (b), (c), and (d) can describe Firm 1's optimal choice. Since it is not possible to find the follower's best response explicitly, we are also not able to find a closed form solution to the leader's problem. However, we may derive some comparative statics results and solve the problem numerically. For any $\mu \in[0,1]$, denote $q_{\mu}^{*}$ Firm 1's optimal choice of $q$. Then $s_{\mu}^{*}\left(q_{\mu}^{*}\right)$ is Firm 2's equilibrium choice of $s$

\footnotetext{
${ }^{16}$ Recall that the parameter $\alpha \in(0,1]$ represents the cost advantage of the leader. Provided there is no imitation, then $\alpha=1$ means that both firms are on the same technological level.
} 
and $q_{\mu}^{*} \pi_{1}\left(s_{\mu}^{*}\left(q_{\mu}^{*}\right)\right)-\frac{1}{2} \alpha\left(q_{\mu}^{*}\right)^{2}$ is the leader's equilibrium profit. The following proposition provides basic comparative statics (see Appendix A for its proof).

Proposition 4. For any $\alpha \in(0,1]$ and $\mu \in[0,1]$, the following statements hold:

(i) If the leader chooses a higher quality in equilibrium (i.e., $q_{\mu}^{*}>\hat{q}_{\mu}$ ), then the leader's equilibrium profit is decreasing in the degree of imitation $\mu$.

(ii) If the leader chooses a lower quality in equilibrium (i.e., $q_{\mu}^{*}<\hat{q}_{\mu}$ ), then both firms' equilibrium strategies $q_{\mu}^{*}$ and $s_{\mu}^{*}\left(q_{\mu}^{*}\right)$, and the leader's equilibrium profit do not depend on the degree of imitation $\mu$.

(iii) If $q_{\mu}^{*} \notin\left\{0, \hat{q}_{\mu}\right\}$, then the leader's equilibrium profit is decreasing in the relative efficiency $\alpha$.

Corollary 2. Consider a fixed $\alpha \in(0,1]$. If $q_{\mu}^{*}<\hat{q}_{\mu}$ for some $\mu \in[0,1)$, then $q_{\mu^{\prime}}^{*}<\hat{q}_{\mu^{\prime}}$ for all $\mu^{\prime} \in[\mu, 1]$.

The first part of the proposition conforms to our intuition that imitation has a positive effect on the follower (see Proposition 2), but a negative effect on the leader, provided the follower prefers a lower quality. On the other hand, if the follower prefers a higher quality, then the equilibrium strategies (and also the leader's profit) do not depend on the degree of imitation. This, together with part (iii) of Proposition 3, directly implies the corollary. Note, however, that although the equilibrium strategies do not depend on $\mu$, the follower's profit does; it is linear and increasing in $\mu$ (see Table 2). The last part of the proposition claims, consistently with intuition, that an increase in the gap between the developed foreign country and the less developed domestic country, benefits the foreign leader.

In order to find the equilibrium choices of qualities, we used numerical simulations. ${ }^{17}$ Our main findings are summarized in two conjectures below. ${ }^{18}$ The first one presents the result for the free-trade regime.

\footnotetext{
${ }^{17}$ Simulations were performed using the Mathematica 5.0 software. We used a grid of $100 \times 100$ in the $(\alpha, \mu)$-space. For each point $(\alpha, \mu)$ from the grid, we verified whether the property holds or not. The program code can be obtained from authors upon request.

${ }^{18} \mathrm{As}$ a byproduct of the simulations, we find that at the point of discontinuity $\hat{q}_{\mu}$, Firm 1's net profit jumps upwards. Hence, since in case (c) Firm 2 is indifferent between choosing qualities $s^{1}(q)$ and $s^{2}(q)$, only the situation when it chooses the former can occur in equilibrium (recall that we analyze pure strategy equilibria).
} 
Conjecture 1. For all $\alpha \in(0,1]$ and $\mu \in[0,1]$, Firm 1 chooses a higher quality in the free-trade regime equilibrium.

Remark 5. Conjecture 1 complements the results by Aoki and Prusa (1997) and Lehmann-Grube (1997). As we already mentioned, both papers analyze sequential choice of qualities with firms having identical cost structure (in a general form). They show that the leader always chooses a higher quality. In our setting this corresponds to the case $\mu=0$ and $\alpha=1$. However, their methods of proofs rely on symmetry and independence of cost functions and cannot be modified to capture imitation, where Firm 1's quality choice also directly affects Firm 2's costs.

The following conjecture characterizes the set of parameters that lead to quality reversal.

Conjecture 2. For any $\mu \in[0,1]$, there is a critical value $\hat{\alpha}_{\mu} \in(0,1)$ such that quality reversal occurs if and only if $\alpha>\hat{\alpha}_{\mu}$. In addition, the critical value $\hat{\alpha}_{\mu}$ is decreasing in the degree of imitation $\mu$.

Figure 6 in Appendix $\mathrm{B}$ shows the values of $\hat{\alpha}_{\mu}$ and the region where quality reversal occurs. ${ }^{19}$ Consider first the free trade regime, and the benchmark case without imitation and when the firms are symmetric in terms of marginal investments efficiencies (i.e., $\alpha=1$ and $\mu=0$ ). In this case, we find that Firm 1, which has a first-mover advantage, produces a higher quality in equilibrium. Clearly, this result is reinforced when $\alpha$ decreases, since a lower value of $\alpha$ benefits Firm 1 even more, by providing it a cost advantage over Firm 2; see also Proposition 4, part (iii). More interestingly, allowing for imitation $(\mu>0)$ does not change the result qualitatively.

An increase in the intensity of imitation $\mu$ has a similar effect as an increase in $\alpha$ (i.e., a negative effect on Firm 1, but a positive effect on Firm 2) and that would in a setup without leadership result, after a certain threshold in relative efficiency is surpassed, in Firm 2 producing a variety of a higher

\footnotetext{
${ }^{19}$ Based on a rough approximation of the critical value $\hat{\alpha}_{\mu}$ (using the same method as above; see Footnote 17), we used further numerical computations in order to evaluate it more precisely. In particular, for each value of $\mu$ from the grid (of size 100 on interval $[0,1])$, we computed the value of $\alpha$ using the bisector method with absolute error less than $10^{-6}$.
} 
quality. ${ }^{20}$ However, the very existence of the leader reverts this, showing the value of first-mover advantage in this setup.

Establishing that Firm 2 always chooses a lower quality in the free trade equilibrium, consider now the trade policy equilibrium. As we already indicated, the trade policy in this setup has a potentially conspicuous effect that may deprive Firm 1 of its leadership position and lead to quality reversal. In order to identify the conditions under which quality reversal occurs, it is sufficient to find out when Firm 2 chooses a higher quality in equilibrium.

Our most striking result is that quality reversal occurs when the firms are symmetric in terms of investment efficiencies, irrespective of imitation. We find that quality reversal occurs for the benchmark case $\mu=0$ and $\alpha=1$. The intuition behind these results stems from the sequencing of moves. If Firm 1 chooses a high quality, it incurs significant costs, that are sunk in later stages. This allows other players who move later, namely Firm 2 and the domestic government, to extract additional revenue. In particular, the domestic government may extract tariff revenues by imposing a high tariff (recall that the optimal tariff is increasing in $s_{1}$ when $s_{1}>s_{2}$ ). This decreases the leader's net profits and may eliminate its first-mover advantage. The leader may, therefore, rather decide to choose a low quality, allowing for quality reversal (see Herguera, Kujal and Petrakis 2002 for a similar intuition). Consequently, quality reversal also occurs for all higher values of $\mu$ (Corollary 2).

On the other hand, lower values of $\alpha$ benefit Firm 1. In the extreme case where $\alpha$ is close to zero (Firm 1's production is almost costless compared to Firm 2's production), we find that Firm 2 always chooses a lower quality, irrespective of the degree of imitation $\mu$. In between, for any fixed $\mu$, there is a critical value of $\alpha$ (denoted $\hat{\alpha}_{\mu}$ ) such that quality reversal occurs if and only if $\alpha$ exceeds this critical value, i.e., the firms are close enough to be symmetric. In addition (see Conjecture 2), the critical value $\hat{\alpha}_{\mu}$ decreases when $\mu$ increases, reflecting the fact that quality reversal is more likely when imitation is easier (high values of $\mu$ ). Intuitively it follows from the fact that

\footnotetext{
${ }^{20}$ Note that in such a setup, but in the absence of leadership, there are two equilibria since each firm can a priori choose either of the quality. Thus, the introduction of leadership in the standard ex-ante symmetric setup helps to establish the uniqueness of equilibrium.
} 
both an increase in $\mu$ and an increase in $\alpha$ have similar effects - they benefit the domestic firm on the expense of the foreign firm.

Remark 6. Conjecture 2 complements the results by Herguera et al. (2002, Proposition 1), who consider the firms to be symmetric and show that under the optimal trade policy the foreign firm always produces a low-quality good in equilibrium. In our setting this corresponds to the special (benchmark) case when $\alpha=1$ and $\mu=0$. However, our results and intuition suggest that when relaxing symmetry (by taking decreasing $\alpha$ ), trade policy may not be sufficient to force the foreign firm to choose a lower quality.

\section{Comparison of FT and TP equilibrium}

In this section, we compare the domestic welfare in the free trade equilibrium with the welfare in the trade policy equilibrium. As it is not possible to characterize these equilibria explicitly, we obtain our results using numerical simulations. We first compare the firms' profits in both regimes and then look at the key determinants of the consumer surplus: average quality, total market size, and its redistribution caused by trade policy. The results are illustrated in Figures 7-10 and summarized in Table 5 in Appendix B. ${ }^{21,22}$

Firms' profits. As expected, Firm 1's profit is harmed in the TP regime due to profit shifting. In particular, for all $\alpha \in(0,1]$ and $\mu \in[0,1]$, Firm 1 earns lower profit (both net and gross) in the TP equilibrium than in the FT equilibrium. On the other hand, this relationship is generally reversed for Firm 2. Its profit (both net and gross) in the FT equilibrium is almost always lower than the (corresponding) profit in the TP equilibrium. ${ }^{23}$

\footnotetext{
${ }^{21}$ The simulations were performed in the same way as described in Footnote 17. Each figure shows the comparison for one particular variable - the shaded area corresponds to the values of parameters $\alpha$ and $\mu$ where its value in the FT equilibrium is higher than its value in the TP equilibrium. Table 5 contains the areas of these regions as shares of the whole region of parameters $(\alpha, \mu)$, i.e., of the set $(0,1] \times[0,1]$. The areas are approximated by the number of grid points in the region.

${ }^{22}$ Table 5 contains the results of more comparisons than presented in this section and shown in Figures. The results of all comparisons can be found in the supplementary Appendix Y available at www. uni-bonn.de/ ${ }^{\sim}$ kovac/papers/it (and from authors upon request).

${ }^{23}$ In both cases, an exception is a small region with area approximately $1 \%$ of the whole feasible region of parameters, as shown in Figures 7 and 8.
} 
Market size and average quality. In a dominant part of the parameter space, the optimal trade policy reduces the market size (or aggregate demand). ${ }^{24}$ The comparison of the market size provides first intuition on the effects on consumers. It, however, does not take into account the product qualities and, therefore, consumers' utilities. A complementary intuition can be provided by comparing the average quality weighted by the market shares. The simulations suggest that the optimal trade policy always reduces the average quality.

Welfare. The effect of trade policy on the consumer surplus may be decomposed into effects on market size (since only consumers who purchase some good obtain a positive utility) and the effect on quality (which determines each consumer's utility). Due to the reduction of the market size and average quality, we might expect that trade policy also tends to reduce the consumer surplus. The simulations indeed confirm this intuition. The optimal trade policy, therefore, benefits only the domestic firm but not consumers. The change in the domestic welfare then depends on the balance of these two effects and, in addition, on the size of tariff revenue (which is zero in the FT equilibrium and positive in the TP equilibrium). The simulations show that the optimal trade policy reduces the domestic welfare compared to the FT regime, when firms are asymmetric enough ( $\alpha$ is small), but increases the domestic welfare when firms are close to being symmetric ( $\alpha$ is close to 1 ) and imitation is not strong ( $\mu$ is not too large); see Figure $10{ }^{25}$ In other words, the considered trade policy is socially beneficial only after the country has reached a certain relative threshold level of economic development (captured by $\alpha$ ), and there is a certain level of intellectual property rights (IPR) protection. Figure 10 also indicates that there is a close relation between

\footnotetext{
${ }^{24} \mathrm{An}$ exception is a small region where no quality reversal occurs (with area approximately $7 \%$, as shown in Figure 9).

${ }^{25}$ Note that the boundary of the region where free trade yields a higher domestic welfare has a kink for $\mu \approx 0.84$ and $\alpha \approx 0.82$. When $\alpha$ increases, the boundary value of $\mu$ lies in the interval $(0.84,0.85)$; simulations with a finer grid indicate that it is in fact downwardsloping. The kink stems from intersection with the region of "corner solution" where it is optimal for Firm 1 to choose $q^{*}=\hat{q}_{\mu}$ (in the FT regime), making Firm 2 indifferent between a higher and a lower quality (see also Footnote 18). The simulations show that this occurs when both $\mu$ and $\alpha$ are sufficiently large. More details can be found in the supplementary Appendix Z available at www. uni-bonn.de/ ${ }^{\sim k o v a c / p a p e r s / i t ~(a n d ~ f r o m ~}$ the authors upon request).
} 
quality reversal and welfare improvements, as summarized in the following conjecture.

Conjecture 3. Under the optimal trade policy Quality reversal is a necessary, but not a sufficient condition for an improvement in domestic welfare (compared to free trade).

The intuition that trade policy might be socially preferable for the domestic country to free trade when the domestic firm produces a higher quality seems apparent (since improvement in domestic gross profit is tremendous and there is a tariff gain in addition). However, the fact that free trade may yield a higher domestic welfare when $\mu$ is large enough even when trade policy leads to quality reversal (as indicated in Figure 10) is somewhat less obvious. To explain this, first recall that the consumer surplus is always higher in the FT regime than in the TP regime. Moreover, an increase in imitation in the FT regime makes price competition tougher ( $s$ increases) and the size of the market larger (the number of consumers served in equilibrium rises with $\mu$ ), this in principle benefits domestic consumers. ${ }^{26}$ At the same time, the size of the consumer surplus is obviously not affected by the change in the imitation parameter $\mu$ when there is trade induced quality reversal; see part (ii) of Proposition 4. Last but not the least, the sunk costs of imitation in the FT regime fall much faster with $\mu$ than in the $\mathrm{TP}$ regime with quality reversal, approaching zero for $\mu$ tending to 1 . (Note that these costs are for any $\mu$ substantially lower in FT regime than in the TP regime since the domestic firm produces a lower quality in free trade.) This, in turn, rapidly decreases the difference in the corresponding net profits of the domestic firm in the FT and the TP regime, respectively. Thus, given the above effects, there is for some given value of $\alpha$ a critical value of $\mu$ beyond which the domestic welfare in the FT regime dominates its counterpart in the TP regime even in the

\footnotetext{
${ }^{26}$ Note that FT dominates TP "excessively" for large values of parameters $\mu$ and $\alpha$ (right upper corner of Figure 10). In this region, there is a "corner solution," as described in Footnotes 18 and 25. Unlike in standard cases where optimal $q$ comes from the "interior" set (i.e., when $q_{\mu}^{*}>\hat{q}_{\mu}$ ), Firm 1's optimal quality $q_{\mu}^{*}$ is now increasing in $\mu$, as it is equal to $\hat{q}_{\mu}$, which we know to be increasing in $\mu$ (see Proposition 3 and Figure 4 ). That in turn, enables Firm 1 to be better off by choosing a higher quality. This phenomenon leads to even a stronger increase in the consumer surplus in $\mu$ compared to the values of $\mu$ that do not yield a "corner solution." It also explains the shape of that region (see also supplementary Appendix Z).
} 
case when trade policy leads to quality reversal. ${ }^{27}$

The policy implications of the above discussion indicate that the LDC government may wish to commit to free trade and strengthen its IPR rights in the cases where the gap in its relative economic development is substantial and where trade in vertically differentiated products prevails in its trade account. This commitment can be induced, for example, by joining a trade organization or signing a bilateral trade agreement.

\section{Conclusion}

The attention of strategic trade policy literature has recently shifted towards international markets in vertically differentiated goods since this framework is particularly suitable for describing international trade between countries at different stages of development. Thus the firms from developed countries are usually associated with a product variety of higher qualities and represent the innovative firms with significant investments into R\&D. On the other hand, firms from less developed countries are associated with lower qualities and less innovative activity. They rather have a tendency to copy or imitate the products by firms from developed countries. Despite the importance of a firm's position as either a leader (innovator) or an imitator (follower) in general and for international trade in particular, current trade literature does not explicitly treat this aspect. Our paper aims to fill this gap by introducing leadership and imitation into the vertical differentiation model of international trade at the LDC market. In this setup, we analyze a time consistent strategic trade policy that appears in a simple and the most common form of import tariff. This is particularly important since the striking effect of trade policy (or, more precisely, its anticipation) in this setup is that it can lead to quality reversal. In other words, it is possible that under certain

\footnotetext{
${ }^{27}$ The phenomenon that strategic trade policy may yield a lower domestic welfare than free trade when the government cannot commit to ex-ante instruments has been observed in a rather different context of standard models with horizontal product differentiation or with homogenous goods where the action takes place in a third market (that is, the domestic welfare coincides with the domestic firm profit net of subsidies; see for instance, Karp and Perloff 1995, Neary and O'Sullivan 1999, Grossman and Maggi 1998, and Neary and Leahy 2000). The intuition for this result lies in manipulative strategic overinvestment by the domestic firm.
} 
conditions the market follower becomes leader in quality! We first show that under free trade, the leader (foreign firm from the DC) always produces a high quality variety. This holds even in the extreme case when the DC firm has no technological advantage and the degree of imitation is high. However, this dramatically changes when we allow for the LDC government to impose a tariff since such trade policy tends to have a positive impact on the follower's profits and enhance its incentives to produce a higher quality, leading to quality reversal. These incentives increase with the degree of imitation or with the decline in the leader's technological advantage. In particular, we show that policy induced quality reversal occurs even when the firms are symmetric in terms of $R \& D$ investment efficiencies, irrespective of the degree of imitation.

The importance of the quality reversal becomes evident after comparison of the domestic welfare. It is indicative that gains in the domestic welfare due to trade policies are closely related to quality reversals. In other words, when the domestic government cannot induce quality reversal using the optimal trade policy, then it may prefer not to adopt the policy and engage in free trade. This may be achieved by a commitment to free trade. A bilateral trade agreement or participation in a trade union can serve as mechanisms to achieve such a commitment. Therefore, our paper provides a rationale for unilateral incentives to adopt free trade.

Our analysis also sheds some light on the commonly known East Asian "economic miracles" since it seems consistent with empirical observations of successful trade and other policies which promoted technological and economic growth. For instance, policy induced quality reversals might also have contributed to Japan's economic success after World War II. Japan started as a less developed country with its firms mostly imitating western products. For example, Japanese photographic industry started its rapid growth in the 1950s with companies like "Nikon and Canon turning out copies and derivatives of German photographic instruments of the time such as the Leica and Contax rangefinder and lenses." 28 After imposing trade policies in order to restrict imports and promote exports, and encouraging imitation (or reverse engineering; see Rodrik 2001), many of Japan's industries (including

\footnotetext{
${ }^{28}$ Source: en.wikipedia.org/wiki/Pentax.
} 
the photographic industry) have evolved into the world's technological and quality leaders. Thus, one of the straightforward extensions of our model is to allow an LDC government to endogenously choose the degree of imitation $\mu$ or a degree of intellectual property rights (IPR) protection, in addition to a tariff. This would enable us to study the interaction of tariffs and IPR protection. $^{29}$

However, our analysis also points to the limitations of the trade policy for spurring economic development and the domestic welfare of an LDC. Namely, the technological gap has to be rather small and imitation (or IPR violation) should not be "too large" for trade policy to be effective in promoting the domestic firm into the position of the technology and market leader and, consequently, increasing the domestic welfare. Arguably, for the vast majority of the LDCs, this is not the case. In this respect, there is a positive trend due to prevailing pressure for global IPR to be strengthened as the results of the Uruguay GATT round and subsequent resolutions of WTO. Thus, some more fundamental policies aimed at the increase of the LDC countries' human capital and technological competence have to be in place much before trade policy would be invoked for the purposes of enhancing domestic firms into the market and as quality leaders.

\footnotetext{
${ }^{29}$ See, for instance, Naghavi (2002) or Žigić (2000) for such an analysis in the nonvertically differentiated market.
} 


\section{References}

Aoki, Reiko and Thomas J. Prusa, "Sequential versus Simultaneous Choice with Endogenous Quality," International Journal of Industrial Organiza, 1997, 15, 103-121.

Bhattacharjea, Aditya, "Strategic Tariffs and Endogenous Market Structure: Trade and Industrial Policies under Imperfect Competition," Journal of Development Economics, 1995, 47, 287-312.

Brander, James A., "Strategic Trade Policy," in Gene M. Grossman and Kenneth S. Rogoff, eds., Handbook of International Economics, Vol. 3, Amsterdam: North-Holland, 1995.

Clark, Don P. and Denise L. Stanley, "Determinants of Intra-Industry Trade between Developing Countries and the United States," Journal of Economic Development, 1999, 24 (2), 79-95.

Etro, Federico, "Innovation by Leaders," The Economic Journal, 2004, 114 (485), 281-303.

, "Aggresive Leaders," The RAND Journal of Economics, 2006a, 37, $1-10$.

_ , "Industrial Policy: A New Approach," Executive Summary 2006b.

Available: www.intertic.org/Strategic Trade Papers/CompetitionPolicy.pdf.

Fershtman, Chaim, "Fixed Rules and Decision Rules, Time Consistency and Subgame Perfection," Economics Letters, 1989, 30, 191-194.

Flam, Harry and Elhanan Helpman, "Vertical Product Differentiation and North-South Trade," The American Economic Review, 1987, 77 (5), $810-822$.

Ghosh, Sibhadip and Satya P. Das, "Strategic Trade Policy and Sustainability," Mimeo, Jan. 2001.

Greenway, David, Robert Hine, and Chris Milner, "Country Specific Factors and the Pattern of Horizontal and Vertical Intra-Industry Trade in the UK," Weltwirtschaftliches Archiv, 1994, 130, 152-174.

Grossman, Gene M. and Giovanni Maggi, "Free Trade vs. Strategic Trade: A Peek into Pandora's Box," CEPR Discussion Paper No. 1784, 1998.

Hallak, Juan Carlos, "Product quality and the direction of trade," Journal of International Economics, 2006, 68, 238-265. 
Herguera, Inigo, Praveen Kujal, and Emmanuel Petrakis, "Tariffs, Quality Reversals and Exit in Vertically Differentiated Industries," Journal of International Economics, 2002, 58, 467-492.

Hoppe, Heidrun C. and Ulrich Lehmann-Grube, "Second-mover Advantages in Dynamic Quality Competition," Mimeo, Hamburg University, February 2001.

Ionaşcu, Delia and Krešimir Žigić, "Free Trade versus Strategic Trade as a Choice between Two 'Second Best' Policies: A Symmetric versus Asymmetric Information Analysis," International Economic Journal, 2005, 19 (3), 417-446.

_ and _ _ "Strategic Tariff Protection, Market Conduct, and Government Commitment Levels in Developing Economies," CERGE-EI Working Paper No. 249, 2005.

Karp, Larry S. and Jeffrey M. Perloff, "The Failure of Strategic Industrial Policies Due to Manipulation by Firms," International Review of Economics and Finance, 1995, 4 (1), 1-16.

Kováč, Eugen, Viatcheslav Vinogradov, and Krešimir Žigić, "Persistence of Monopoly, Innovation, and R\&D Spillovers: Static versus Dynamic Analysis," CERGE-EI Working Paper No. 316, January 2007.

Kúnin, Michael and Krešimir Žigić, "Strategic Trade Policy and Vertical Product Differentiation: Intra-industry Trade Between Developed and Developing Countries," CERGE-EI Working Paper No. 230, 2004.

Lehmann-Grube, Ulrich, "Strategic Choice of Quality when Quality is Costly - the Persistence of the High Quality Advantage," The RAND Journal of Economics, 1997, 28, 372-384.

Moraga-Gonzáles, José Luis and Jean-Marie Viaene, "Trade Policy and Quality Leadership in Transition Economies," European Economic Review, 2005, 49 (2), 359-385.

Motta, Massimo, Jacques-Francois Thisse, and Antonio Cabrales, "On the Persistence of Leadership or Leapfrogging in International Trade," International Economic Review, 1997.

Naghavi, Alireza, "Strategic Intellectual Property Protection Policy and North-South Technology Transfer," Mimeo, University College Dublin and Universitá Bocconi, Jan. 2002. 
Neary, J. Peter and Dermot Leahy, "Strategic Trade and Industrial Policy towards Dynamic Oligopolies," The Economic Journal, 2000, 110, 484-508.

_ and Paul O'Sullivan, "Beat 'Em or Join 'Em?: Export Subsidies Versus International Research Joint Ventures in Oligopolistic Markets," Scandinavian Journal of Economics, 1999, 101 (4), 577-596.

Pepall, Lynne, "Imitative Competition and Product Innovation in a Duopoly Model," Economica, 1997, 64 (254), 265-279.

Rodrik, Dani, "The global governance of trade as if development really mattered," Mimeo, paper prepared for the UNDP, 2001. Available: ksghome.harvard.edu/ ${ }^{d r o d r i k / U N D P t r a d e . P D F . ~}$

Schott, Peter K., "Across-Product versus Within-Product Specialization in International Trade," The Quarterly Journal of Economics, 2004, 119 (2), 647-678.

Shaked, Avner and John Sutton, "Relaxing Price Competition Through Product Differentiation," Review of Economic Studies, 1982, 49 (1), 313.

_ and _ _ , "Natural Oligopolies," Econometrica, 1983, 51 (5), 1469 1483.

__ and _ _ , "Product Differentiation and Industrial Structure," Journal of International Economics, 1987, 36 (2), 131-146.

Staiger, Robert W., "International Rules and Institutions for Trade Policy," in Gene M. Grossman and Kenneth S. Rogoff, eds., The Handbook of International Economics, Vol. 3, Amsterdam: North-Holland, 1995.

Tirole, Jean, The Theory of Industrial Organization, 5th ed., Cambridge, Massachusetts: The MIT Press, 1992.

Zhou, Dongsheng, Barbara J. Spencer, and Ilan Vertinsky, "Strategic Trade Policy with Endogeneous Choice of Quality and Asymmetric Costs," NBER Working Paper No. 7536, 2000.

, and ___ , "Strategic Trade Policy with Endogeneous Choice of Quality and Asymmetric Costs," Journal of International Economics, 2002, 56, 205-232.

Žigić, Krešimir, "Strategic Trade Policy, Intellectual Property Rights Protection, and North-South Trade," Journal of Development Economics, 2000, 61 (1), 27-60. 


\section{A Appendix: Proofs}

Derivation of Firm 2's cost function. According to condition (i), without imitation, Firm 2's cost function can be written as $\frac{1}{2} \gamma_{2} s_{2}^{2}$, where $\gamma_{2}$ is a constant such that $\gamma_{2} \geq \gamma_{1}$. This yields marginal costs $\gamma_{2} s_{2}$. According to (iii), these are also Firm 2's marginal costs when $s_{2}>s_{1}$. On the other hand, when $s_{2} \leq s_{1}$, the marginal costs can be, due to (ii), written as $\gamma_{2}(1-\mu) s_{2}$, where $\mu \in[0,1]$ is a constant (parameter) representing the degree of imitation. After integration, we obtain that Firm 2's cost function has the following form

$$
C_{2}\left(s_{1}, s_{2}\right)= \begin{cases}\frac{1}{2} \gamma_{2}(1-\mu) s_{2}^{2}+\xi_{1}, & \text { if } s_{2} \leq s_{1}, \\ \frac{1}{2} \gamma_{2} s_{2}^{2}+\xi_{2}, & \text { if } s_{2}>s_{1}\end{cases}
$$

where $\xi_{1}$ and $\xi_{2}$ are some constants. Since for $\mu=0$ (no imitation), Firm 2 's cost function needs to be equal to $\frac{1}{2} \gamma_{2} s_{2}^{2}$, due to condition (i), then it is necessary that $\xi_{1}=0$. Moreover, due to condition (iv), the cost function is continuous when $s_{2}=s_{1}$. Hence, $\frac{1}{2} \gamma_{2}(1-\mu) s_{1}^{2}=\frac{1}{2} \gamma_{2} s_{1}^{2}+\xi_{2}$, which yields $\xi_{2}=-\frac{1}{2} \gamma_{2} \mu s_{1}^{2}$. Summarizing, we obtain the expression given by (4).

Proof of Lemma 1. Since $\pi_{2}^{\prime}(0)-q c_{2}^{\prime}(0)>0>\pi_{2}^{\prime}(1)-q c_{2}^{\prime}(1)$ for any $q \geq 0$, then (because of continuity) there always exists a solution of (16) on interval $(0,1)$. Due to concavity, this solution is unique and represents the maximum of Firm 2's net profit on $(0,1)$.

Proof of Lemma 2. If $q \geq \frac{4}{9}$, then $\pi_{2}^{\prime}(s)<q c_{2}^{\prime}(s)$ for all $s>1$ in the FT regime, since the line $q c_{2}^{\prime}(s)$ lies above the graph of $\pi_{2}^{\prime}(s)$. In this case $\pi_{2}(s)-$ $q c_{2}(s)$ is decreasing, and hence, is negative on $[1, \infty)$. On the other hand, if $q<\frac{4}{9}$, then $\pi_{2}^{\prime}(1)-q c_{2}^{\prime}(1)>0$. Moreover, $\pi_{2}^{\prime}(s)-q c_{2}^{\prime}(s) \rightarrow-\infty$ as $s \rightarrow \infty$ (see Table 3 ). Then (because of continuity), there always exists a solution of $(16)$ on interval $(1, \infty)$. Due to concavity, this solution is unique and represents the maximum of Firm 2's net profit on $(1, \infty)$.

The proof for the TP regime is analogous.

Proof of Lemma 3. Recall that $s^{1}(q)$ and $s^{2}(q)$ are (unique) solutions of (16) when $s<1$ and $s>1$, respectively. The continuity of the first derivative follows from the implicit function theorem ${ }^{30}$ since both $\pi_{2}^{\prime}$ and $c_{2}^{\prime}$ are $\mathcal{C}^{1}$.

${ }^{30}$ Note that $\frac{\mathrm{d}}{\mathrm{d} s}\left[\pi_{2}^{\prime}(s)-q c_{2}^{\prime}(s)\right] \neq 0$, since $c_{2}^{\prime \prime}>0$ and $\pi_{2}^{\prime \prime}<0$. 
The Implicit Function Theorem also implies that

$$
\left[\pi_{2}^{\prime \prime}\left(s^{j}(q)\right)-q c_{2}^{\prime \prime}\left(s^{j}(q)\right)\right] \frac{\mathrm{d} s^{j}(q)}{\mathrm{d} q}=c_{2}^{\prime}\left(s^{j}(q)\right)
$$

for $j=1,2$. Since $c_{2}^{\prime}>0, c_{2}^{\prime \prime}>0$, and $\pi_{2}^{\prime \prime}<0$, we obtain $\mathrm{d} s^{j}(q) / \mathrm{d} q<0$, which completes the proof.

Proof of Proposition 1. Let us denote

$$
\Delta(q)=\left[\pi_{2}\left(s^{2}(q)\right)-q c_{2}\left(s^{2}(q)\right)\right]-\left[\pi_{2}\left(s^{1}(q)\right)-q c_{2}\left(s^{1}(q)\right)\right],
$$

which represents the difference between Firm 2's maximal net profits when it chooses $s<1$ and when it chooses $s>1$. Therefore, $s^{*}(q)=s^{1}(q)$ if $\Delta(q)<0$ and $s^{*}(q)=s^{2}(q)$ if $\Delta(q)>0$. We will show that $\Delta(q)$ is decreasing and attains a positive value when $q \rightarrow 0^{+}$and a negative value when $q \rightarrow \bar{q}^{-}$. Since $\Delta(q)$ is continuous, this would mean that there exists $\hat{q} \in(0, \bar{q})$ such that $\Delta(\hat{q})=0$. Clearly, the value of $\hat{q}$ depends only on the parameter $\mu$ (and not on $\gamma_{1}$ and $\left.\gamma_{2}\right)$. Due to monotonicity, $\Delta(q)>0$ when $q<\hat{q}$ and $\Delta(q)<0$ when $q>\hat{q}$.

Now it remains to show that $\Delta(q)$ is decreasing and attains a positive value when $q \rightarrow 0^{+}$and a negative value when $q \rightarrow \bar{q}^{-}$. First consider $q \rightarrow \bar{q}^{-}$. In this case, $s^{2}(q) \rightarrow 1$ and consequently $\pi_{2}\left(s^{2}(q)\right)-q c_{2}\left(s^{2}(q)\right)<0$. Since the net profit for $s^{1}(q)$ is always positive (as optimal net profit when $s<1)$, then $\Delta(q)<0$ when $q$ is close to $\bar{q}$. Note also that $s^{1}(q) \rightarrow 0$ when $q \rightarrow \infty$ (see Figure 2).

Now consider $q \rightarrow 0^{+}$. In this case, we get $s^{1}(q) \rightarrow \frac{4}{7}$ in the FT regime and $s^{1}(q) \rightarrow \frac{2}{3}$ in the TP regime (see Table 3 and Figure 2). Consequently, $\pi_{2}\left(s^{1}(q)\right)-q c_{2}\left(s^{1}(q)\right)$ is bounded when $q \rightarrow 0^{+}$. In addition, $s^{2}(q) \rightarrow \infty$ (see Table 3 and Figure 2) and $\pi_{2}\left(s^{2}(q)\right)-q c_{2}\left(s^{2}(q)\right) \rightarrow \infty$. This can be obtained from the following computation:

$$
\begin{aligned}
\pi_{2}\left(s^{2}(q)\right)-q c_{2}\left(s^{2}(q)\right) & =\pi_{2}\left(s^{2}(q)\right)-\frac{1}{2}\left[s^{2}(q)\right]^{2} q+\mu q= \\
& =\pi_{2}\left(s^{2}(q)\right)-\frac{1}{2} s^{2}(q) \pi_{2}^{\prime}\left(s^{2}(q)\right)+\mu q
\end{aligned}
$$

where we used (16): $q s^{2}(q)=\pi_{2}^{\prime}\left(s^{2}(q)\right)$. When $q \rightarrow 0^{+}$, the last term $\mu q$ 
converges to zero and the rest to infinity, since $\pi_{2}(s)-\frac{1}{2} s \pi_{2}^{\prime}(s) \rightarrow \infty$ as $s \rightarrow \infty .{ }^{31}$ Hence we obtain $\Delta(q) \rightarrow \infty$ when $q \rightarrow 0^{+}$.

As the last step, we will show that $\Delta(q)$ is decreasing. Now recall that $s^{1}(q)$ and $s^{2}(q)$ represent local minima of Firm 2's net profit $\pi_{2}(s)-q c_{2}(s)$. Thus, it follows from the Envelope Theorem that

$$
\frac{\mathrm{d} \Delta(q)}{\mathrm{d} q}=-c_{2}\left(s^{2}(q)\right)+c_{2}\left(s^{1}(q)\right)
$$

This is negative, since $c_{2}(q)$ is increasing and by definition $s^{1}(q)<1<$ $s^{2}(q)$.

Proof of Proposition 2. The proposition follows from the Envelope Theorem. In particular, we obtain that the derivative of Firm 2's optimal profit with respect to $\mu$ is equal to $\frac{1}{2} q\left[s^{1}(q)\right]^{2}$ when $q>\hat{q}_{\mu}$, and to $\frac{1}{2} q$ when $q<\hat{q}_{\mu}$. Obviously, it is positive in both cases (when $q \neq 0$ ).

Proof of Proposition 3. The claim that $s^{*}$ is increasing in $\mu$ (for a fixed $q$ ) is simply a consequence of statements (i)-(iii). We will prove each of them separately.

(i) The proof that $s_{\mu}^{1}$ is increasing in $\mu$ is analogous to the proof that $s_{\mu}^{1}$ is decreasing in $q$, since $s_{\mu}^{1}$ depends only on the product $q \cdot(1-\mu)$; see the Proof of Lemma 3.

(ii) In order to establish that this solution does not depend on $\mu$, it is sufficient to recognize that the derivatives of Firm 2's gross profits and costs also do not depend on the parameter $\mu$; see the Proof of Lemma 2.

(iii) Let $s_{\mu}^{1}$ and $s_{\mu}^{2}$ denote the values of $s^{1}$ and $s^{2}$ that are chosen for $q=\hat{q}_{\mu}$. The values of $s_{\mu}^{1}, s_{\mu}^{2}$, and $\hat{q}_{\mu}$ are determined simultaneously by the system of three equations introduced above the proposition. According to the last equation

$$
\pi_{2}\left(s_{\mu}^{1}\right)-\frac{1}{2}(1-\mu) \hat{q}_{\mu}\left(s_{\mu}^{1}\right)^{2}=\pi_{2}\left(s_{\mu}^{2}\right)-\frac{1}{2} \hat{q}_{\mu}\left[\left(s_{\mu}^{2}\right)^{2}-\mu\right] .
$$

\footnotetext{
${ }^{31}$ It can be easily established that $\pi_{2}(s)-\frac{1}{2} s \pi_{2}^{\prime}(s)$ is equal to $2 s^{3}(4 s-7) /(4 s-1)^{3}$ in the FT regime and to $9 s^{3}(2 s-3)(2 s-1)\left(12 s^{2}-13 s+4\right) /\left[2(4 s-1)^{3}(3 s-2)^{3}\right]$ in the TP regime. Both these expressions diverge to infinity when $s \rightarrow \infty$.
} 
Taking the derivative with respect to $\mu$ (and using the implicit function theorem) we obtain

$$
\begin{gathered}
{\left[\pi_{2}^{\prime}\left(s_{\mu}^{1}\right)-(1-\mu) \hat{q}_{\mu} s_{\mu}^{1}\right] \frac{\mathrm{d} s_{\mu}^{1}}{\mathrm{~d} \mu}+\frac{1}{2} \hat{q}_{\mu}\left(s_{\mu}^{1}\right)^{2}-\frac{1}{2}(1-\mu)\left(s_{\mu}^{1}\right)^{2} \frac{\mathrm{d} \hat{q}_{\mu}}{\mathrm{d} \mu}=} \\
=\left[\pi_{2}^{\prime}\left(s_{\mu}^{2}\right)-\hat{q}_{\mu} s_{\mu}^{2}\right] \frac{\mathrm{d} s_{\mu}^{2}}{\mathrm{~d} \mu}+\frac{1}{2} \hat{q}_{\mu}-\frac{1}{2}\left[\left(s_{\mu}^{2}\right)^{2}-\mu\right] \frac{\mathrm{d} \hat{q}_{\mu}}{\mathrm{d} \mu} .
\end{gathered}
$$

According to the first-order conditions (first and second equation), the first term on the left-hand side and the first term on the right-hand side are equal to zero. Therefore,

$$
\left[\left(s_{\mu}^{2}\right)^{2}-\mu-(1-\mu)\left(s_{\mu}^{1}\right)^{2}\right] \frac{\mathrm{d} \hat{q}_{\mu}}{\mathrm{d} \mu}=\hat{q}_{\mu}\left[1-\left(s_{\mu}^{1}\right)^{2}\right]
$$

which means that $\mathrm{d} \hat{q}_{\mu} / \mathrm{d} \mu>0$, since $\left(s_{\mu}^{2}\right)^{2}-\mu-(1-\mu)\left(s_{\mu}^{1}\right)^{2}=2\left[c_{2}\left(s_{\mu}^{2}\right)-\right.$ $\left.c_{2}\left(s_{\mu}^{1}\right)\right]>0$ (as $c_{2}$ is increasing) and $s_{\mu}^{1}<1$.

Proof of Lemma 4. (i) If $q \rightarrow \infty$, then $q>\hat{q}_{\mu}, s^{*}(q)=s^{1}(q)$, and it follows from part (iv) of Corollary 1 that $s^{*}(q) \rightarrow 0^{+}$. In addition, $\pi_{1}(s)$ is bounded in some neighborhood of $s=0$, as it converges to a finite limit when $s \rightarrow 0^{+}$(see Table 2 ). Thus, $q \pi_{1}(s)-\frac{1}{2} \alpha q^{2}$ diverges to $-\infty$.

(ii) If $q \rightarrow 0^{+}$, then $q<\hat{q}_{\mu}, s^{*}(q)=s^{2}(q)$, and it follows from part (iv) of Corollary 1 that $s^{*}(q) \rightarrow \infty$. Again, $\pi_{1}(s)$ is bounded when $s$ is sufficiently large, as it converges to a finite limit (which is $\frac{1}{16}$ in the FT regime and $\frac{1}{144}$ in the TP regime), when $s \rightarrow \infty$ (see Table 2). Hence, $q \pi_{1}(s)-\frac{1}{2} \alpha q^{2}$ converges to zero.

(iii) The derivative of Firm 1's continuation net profit with respect to $q$ is

$$
\pi_{1}\left(s^{*}(q)\right)+q \pi_{1}^{\prime}\left(s^{*}(q)\right) \frac{\mathrm{d} s^{*}(q)}{\mathrm{d} q}-\alpha q .
$$

Now recall that for $q$ sufficiently small $\left(q<\hat{q}_{\mu}\right)$ we get $s^{*}(q)=s^{2}(q)$, which is continuously differentiable. Therefore, it is sufficient to show that the above derivative is positive when $q \rightarrow 0^{+}$. In that case $s^{*}(q) \rightarrow$ 
$\infty$. We have already established in part (ii) that $\pi_{1}(s)$ converges to a positive limit when $s \rightarrow \infty$. Thus, the first term in (19) is positive when $q \rightarrow 0^{+}$. Obviously, the last term converges to zero in that case. We will show now that $A=\pi_{1}^{\prime}\left(s^{*}(q)\right) \frac{\mathrm{d} s^{*}(q)}{\mathrm{d} q}$ has a finite limit (when $q \rightarrow 0^{+}$), which implies that the second term (equal to $q A$ ) also converges to zero when $q \rightarrow 0^{+}$. For this recall that the first-order condition for Firm 2 's profit maximization is $\pi_{2}^{\prime}(s)=q s$. In addition, it follows from the proof of Lemma 3 that

$$
\frac{\mathrm{d} s^{*}(q)}{\mathrm{d} q}=\frac{s}{\pi_{2}^{\prime \prime}(s)-q}=\frac{s^{2}}{s \pi_{2}^{\prime \prime}(s)-\pi_{2}^{\prime}(s)}
$$

We may, therefore, rewrite $A$ in terms of $s$ and take the limit $s \rightarrow \infty$. We obtain $A=s^{2} \pi_{1}^{\prime}(s) /\left[s \pi_{2}^{\prime \prime}(s)-\pi_{2}^{\prime}(s)\right]$, which after computing the derivatives (from Tables 3 and 4 ) implies that in the FT and the TP regime:

$$
\begin{aligned}
& A^{\mathrm{FT}}=-\frac{(2 s+1)(4 s-1)}{4\left(16 s^{2}-16 s+21\right)} \\
& A^{\mathrm{TP}}=-\frac{(s-1)^{2}(2 s-1)(3 s-2)(4 s-1)(7 s+2)}{9\left(576 s^{6}-2112 s^{5}+3684 s^{4}-3504 s^{3}+1909 s^{2}-568 s+72\right)} .
\end{aligned}
$$

Thus, $A^{\mathrm{FT}}$ converges to $-\frac{1}{8}$ and $A^{\mathrm{TP}}$ converges to $-\frac{7}{216}$, when $s \rightarrow \infty$. This completes the proof.

Proof of Proposition 4. (i) The Envelope Theorem implies that the (total) derivative of Firm 1's optimal profit is equal to

$$
\frac{\partial}{\partial \mu}\left[q \pi_{1}\left(s_{\mu}^{1}(q)\right)-\frac{1}{2} \alpha q^{2}\right]=q \pi_{1}^{\prime}\left(s_{\mu}^{1}(q)\right) \frac{\partial s_{\mu}^{1}(q)}{\partial \mu}
$$

evaluated at the optimal value of $q$. It follows from part (i) of Proposition 3 that $\partial s_{\mu}^{1}(q) / \partial \mu>0$. In addition, it can be easily established that $\pi_{1}^{\prime}(s)<0$ when $s<1$ (see the expressions in Table 4). This completes the proof.

(ii) The claim follows directly from from two facts. First, Firm 1's (net) profit does not depend on $\mu$ directly. Second, according to part (ii) of 
Proposition 3, Firm 2's best response does not depend on $\mu$, whenever it leads to a higher quality, i.e., when $s^{*}(q)>1$.

(iii) The claim follows directly from the Envelope Theorem and from the fact that Firm 2's maximization problem (for a fixed $q$ ) and, hence, its best response function $s^{*}$ do not depend on $\alpha$. 


\section{B Appendix: Figures and tables}

\begin{tabular}{cccc}
\hline & $\begin{array}{c}\text { Qualities } \\
\text { ranking }\end{array}$ & \multicolumn{2}{c}{ Continuation profit $\Pi_{i}\left(s_{1}, s_{2}\right)$} \\
FT regime & TP regime \\
\hline Firm 1 & $s_{1}>s_{2}$ & $\frac{4 s_{1}^{2}\left(s_{1}-s_{2}\right)}{\left(4 s_{1}-s_{2}\right)^{2}}$ & $\frac{s_{1}^{2}\left(s_{1}-s_{2}\right)\left(4 s_{1}-3 s_{2}\right)^{2}}{\left(3 s_{1}-2 s_{2}\right)^{2}\left(4 s_{1}-s_{2}\right)^{2}}$ \\
& $s_{1}<s_{2}$ & $\frac{s_{2} s_{1}\left(s_{2}-s_{1}\right)}{\left(4 s_{2}-s_{1}\right)^{2}}$ & $\frac{s_{2} s_{1}\left(s_{2}-s_{1}\right)^{3}}{\left(3 s_{2}-2 s_{1}\right)^{2}\left(4 s_{2}-s_{1}\right)^{2}}$ \\
\hline Firm 2 & $s_{1}>s_{2}$ & $\frac{s_{1} s_{2}\left(s_{1}-s_{2}\right)}{\left(4 s_{1}-s_{2}\right)^{2}}$ & $\frac{4 s_{1} s_{2}\left(s_{1}-s_{2}\right)\left(2 s_{1}-s_{2}\right)^{2}}{\left(3 s_{1}-2 s_{2}\right)^{2}\left(4 s_{1}-s_{2}\right)^{2}}$ \\
& & $\frac{4 s_{2}^{2}\left(s_{2}-s_{1}\right)}{\left(4 s_{2}-s_{1}\right)^{2}}$ & $\frac{9 s_{2}^{2}\left(s_{2}-s_{1}\right)\left(2 s_{2}-s_{1}\right)^{2}}{\left(3 s_{2}-2 s_{1}\right)^{2}\left(4 s_{2}-s_{1}\right)^{2}}$ \\
\hline
\end{tabular}

Table 1: Continuation profits $\Pi_{1}\left(s_{1}, s_{2}\right)$ and $\Pi_{2}\left(s_{1}, s_{2}\right)$ of Firm 1 (leader) and Firm 2 (follower)

\begin{tabular}{ccccc}
\hline & \multicolumn{2}{c}{ Continuation profit $\pi_{i}(s)$} & Costs \\
& FT regime & TP regime & \\
\hline Firm 1 $s<1$ & $\frac{4(1-s)}{(4-s)^{2}}$ & $\frac{(1-s)(4-3 s)^{2}}{(3-2 s)^{2}(4-s)^{2}}$ & $\frac{1}{2} \alpha$ \\
& \multirow{2}{*}{$s>1$} & $\frac{s(s-1)}{(4 s-1)^{2}}$ & $\frac{s(s-1)^{3}}{(3 s-2)^{2}(4 s-1)^{2}}$ & $\frac{1}{2} \alpha$ \\
\hline Firm 2 & $s<1$ & $\frac{s(1-s)}{(4-s)^{2}}$ & $\frac{4 s(1-s)(2-s)^{2}}{(3-2 s)^{2}(4-s)^{2}}$ & $\frac{1}{2}(1-\mu) s^{2}$ \\
& \multirow{2}{*}{$s>1$} & $\frac{4 s^{2}(s-1)}{(4 s-1)^{2}}$ & $\frac{9 s^{2}(s-1)(2 s-1)^{2}}{(3 s-2)^{2}(4 s-1)^{2}}$ & $\frac{1}{2}\left(s^{2}-\mu\right)$ \\
\hline
\end{tabular}

Table 2: Continuation profits $\pi_{1}(s), \pi_{2}(s)$, and $\operatorname{costs} c_{1}, c_{2}(s)$ after substitution 


\begin{tabular}{|c|c|c|}
\hline \multicolumn{3}{|c|}{ Derivative $\pi_{2}^{\prime}(s)$} \\
\hline & FT regime & TP regime \\
\hline \multirow{2}{*}{$s<1$} & $4-7 s$ & $4(2-3 s)(2-s)\left(12-13 s+4 s^{2}\right)$ \\
\hline & $\overline{(4-s)^{3}}$ & $(4-s)^{3}(3-2 s)^{3}$ \\
\hline \multirow{2}{*}{$s>1$} & $4 s\left(4 s^{2}-3 s+2\right)$ & $9 s(2 s-1)\left(24 s^{4}-54 s^{3}+51 s^{2}-22 s+4\right)$ \\
\hline & $(4 s-1)^{3}$ & $(4 s-1)^{3}(3 s-2)^{3}$ \\
\hline$s=0$ & $\frac{1}{16}$ & $\frac{1}{9}$ \\
\hline$s \rightarrow 1^{-}$ & $-\frac{1}{9}$ & $-\frac{4}{9}$ \\
\hline$s \rightarrow 1^{+}$ & $\frac{4}{9}$ & 1 \\
\hline$s \rightarrow \infty$ & $\frac{1}{4}$ & $\frac{1}{4}$ \\
\hline
\end{tabular}

Table 3: Derivative of Firm 2's profit $\pi_{2}(s)$ and some of its values

\begin{tabular}{lcc}
\hline & FT regime & $\begin{array}{c}\text { Derivative } \pi_{1}^{\prime}(s) \\
\text { TP regime }\end{array}$ \\
\hline$s<1$ & $-\frac{4(2+s)}{(4-s)^{3}}$ & $-\frac{(4-3 s)\left(32-32 s-3 s^{2}+6 s^{3}\right)}{(4-s)^{3}(3-2 s)^{3}}$ \\
$s>1$ & $-\frac{2 s+1}{(4 s-1)^{3}}$ & $\frac{(s-1)(2 s-1)(7 s+2)}{(4 s-1)^{3}(3 s-2)^{3}}$ \\
\hline$s=0$ & $-\frac{1}{8}$ & $-\frac{2}{27}$ \\
$s \rightarrow 1^{-}$ & $-\frac{4}{9}$ & $-\frac{1}{9}$ \\
$s \rightarrow 1^{+}$ & $\frac{1}{9}$ & 0 \\
$s \rightarrow \infty$ & 0 & 0 \\
\hline
\end{tabular}

Table 4: Derivative (with respect to $s$ ) of Firm 1's profit $\pi_{1}(s)$ and some of its values 


\begin{tabular}{|c|c|c|c|}
\hline Variable & Notation & Firm 1 & Firm 2 \\
\hline net profit & $\Pi_{i}-C_{i}$ & $100 \%$ & $<1 \%$ \\
\hline gross profit & $\Pi_{i}$ & $100 \%$ & $1 \%$ \\
\hline price & $p_{i}$ & $100 \%$ & $6 \%$ \\
\hline quality & $s_{i}$ & $100 \%$ & $6 \%$ \\
\hline hedonic price & $p_{i} / s_{i}$ & $21 \%$ & $7 \%$ \\
\hline quality ratio & $s=s_{2} / s_{1}$ & \multicolumn{2}{|c|}{$0 \%$} \\
\hline quality gap* & $s_{i} / s_{j}$ & \multicolumn{2}{|c|}{$49 \%$} \\
\hline market size* & $1-\theta_{j 0}$ & \multicolumn{2}{|c|}{$93 \%$} \\
\hline average quality* & $\begin{aligned} &\left(1-\theta_{i j}\right) s_{i}+ \\
&+\left(\theta_{i j}-\theta_{j 0}\right) s_{j}\end{aligned}$ & \multicolumn{2}{|c|}{$100 \%$} \\
\hline consumer surplus & $C S$ & \multicolumn{2}{|c|}{$100 \%$} \\
\hline domestic welfare & $D W$ & \multicolumn{2}{|c|}{$80 \%$} \\
\hline quality reversal & & \multicolumn{2}{|c|}{$51 \%$} \\
\hline
\end{tabular}

Table 5: Comparison of FT and TP equilibrium (numerical simulations)

${ }^{*}$ The formulas correspond to the case $s_{i}>s_{j}$.

Note: For each variable, the number represents the area of the range of parameters where its value in the FT equilibrium is higher than in the TP equilibrium (expressed as the share of the whole range of parameters); see Figures 7-10. Provided that the joint distribution of $\alpha$ and $\mu$ is roughly uniform, then it represents the probability that its value in the FT equilibrium is higher than in the TP equilibrium. 


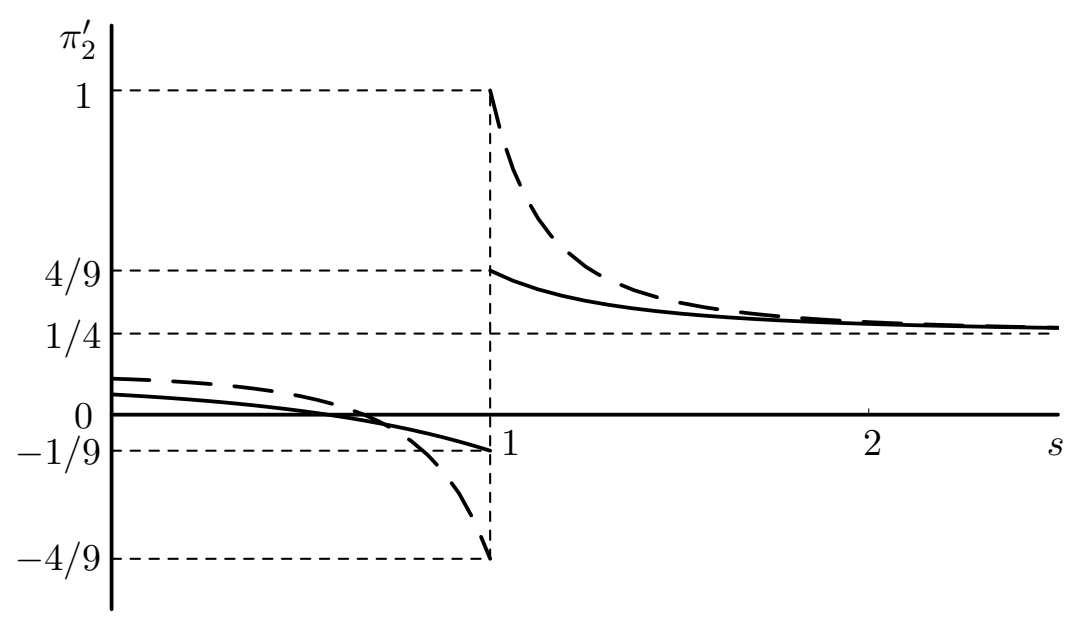

Figure 1: Derivative of Firm 2's profit $\pi_{2}^{\prime}(s)$ in the free trade regime (solid lines) and under optimal trade policy (dashed lines)

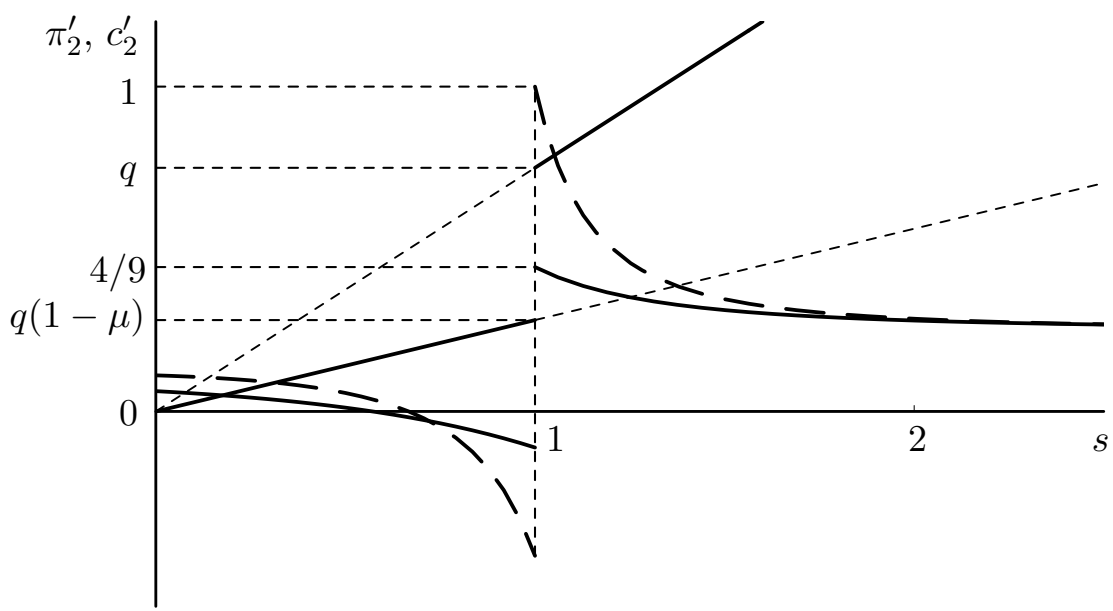

Figure 2: Derivatives of Firm 2's profit $\pi_{2}^{\prime}(s)$ and $\operatorname{costs} c_{2}^{\prime}(s)$ 


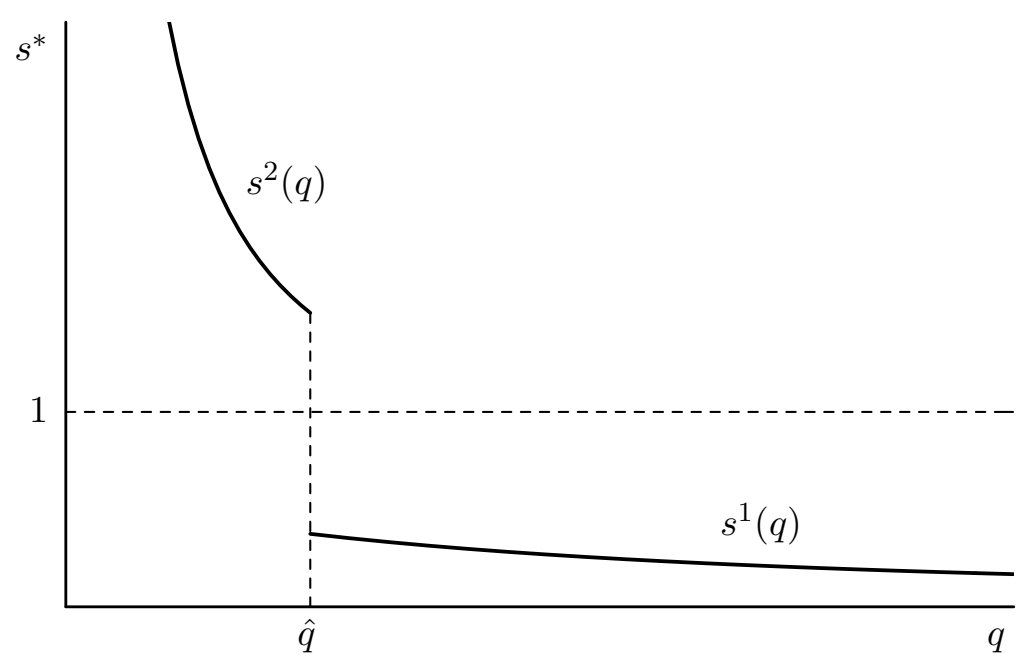

Figure 3: Firm 2's best response $s^{*}(q)$

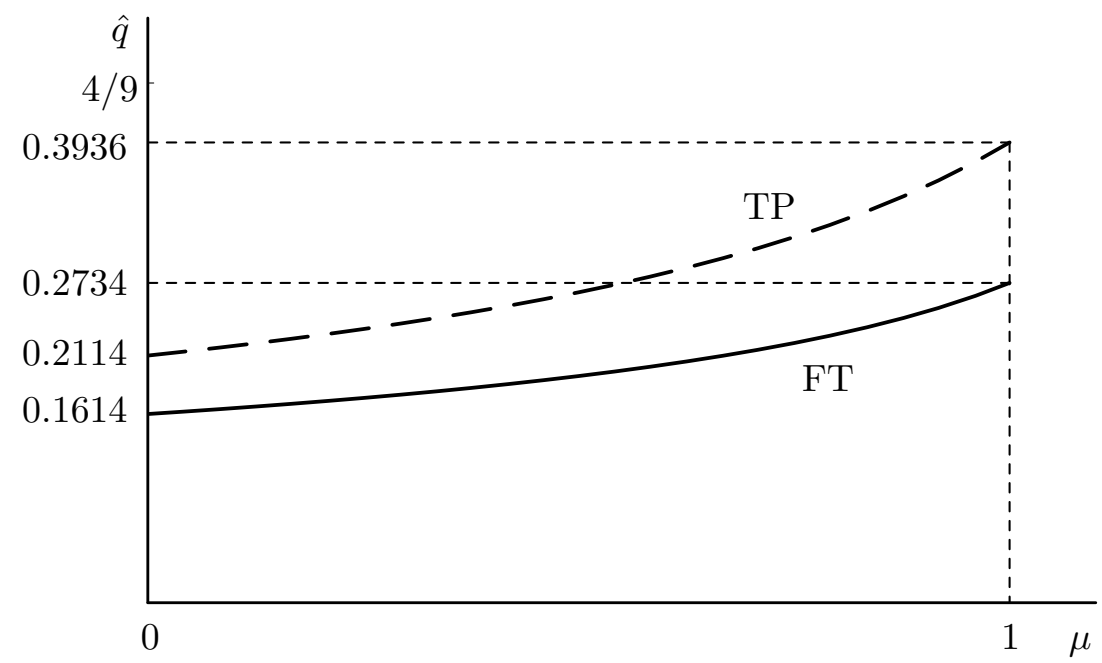

Figure 4: Profile of $\hat{q}$ in the free trade regime (solid line) and under optimal trade policy (dashed line); obtained numerically 


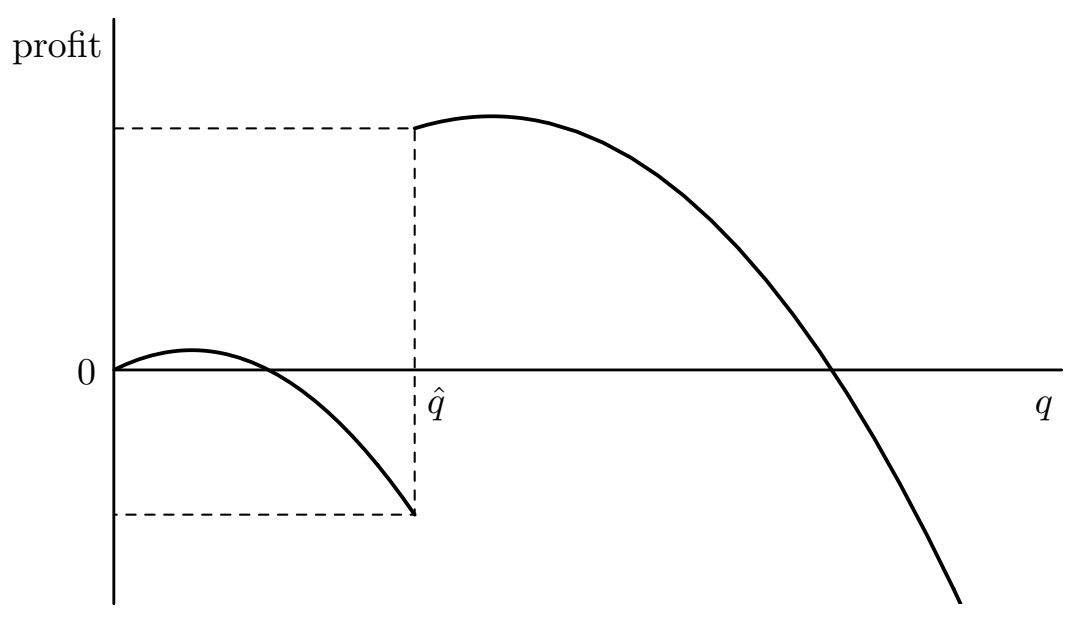

Figure 5: Leader's net (continuation) profit $q \pi_{1}\left(s^{*}(q)\right)-\frac{1}{2} \alpha q^{2}$ (numerical example: FT regime, $\left.\alpha=\frac{7}{8}, \mu=\frac{1}{4}\right)$

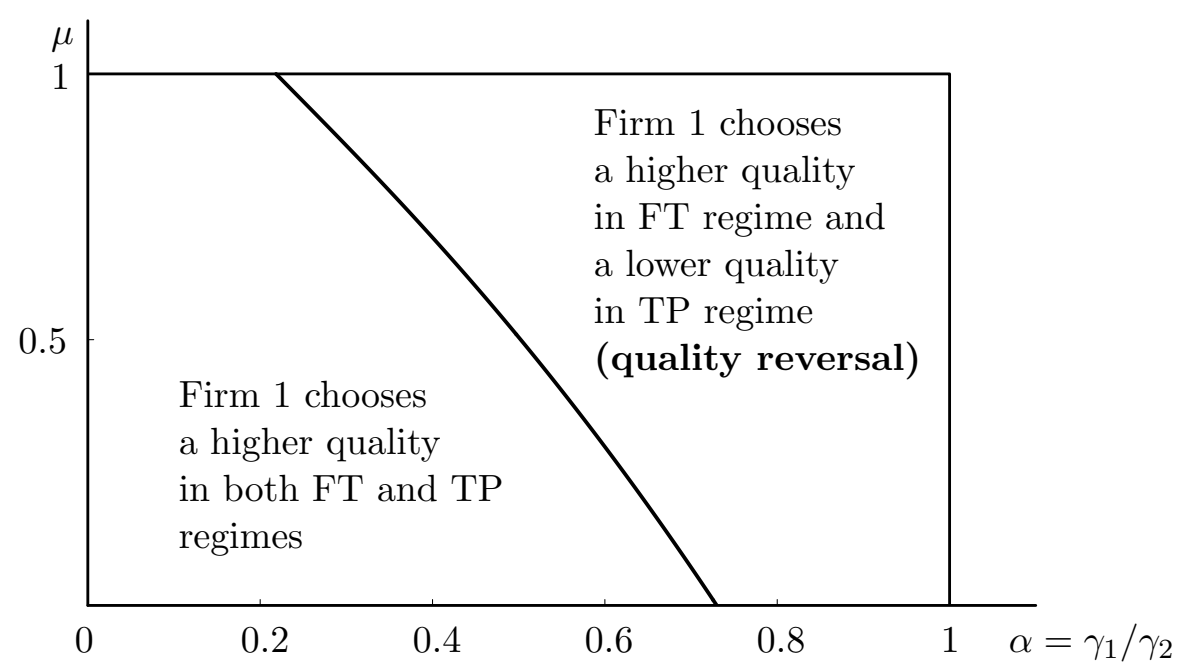

Figure 6: Region with quality reversal (numerical simulations) 
Note: Each of the following figures shows the comparison of some variable in the FT equilibrium and in the TP equilibrium. The shaded area corresponds to the values of parameters $\alpha$ and $\mu$ where the equilibrium value of the variable in the FT equilibrium is higher than in the TP equilibrium.

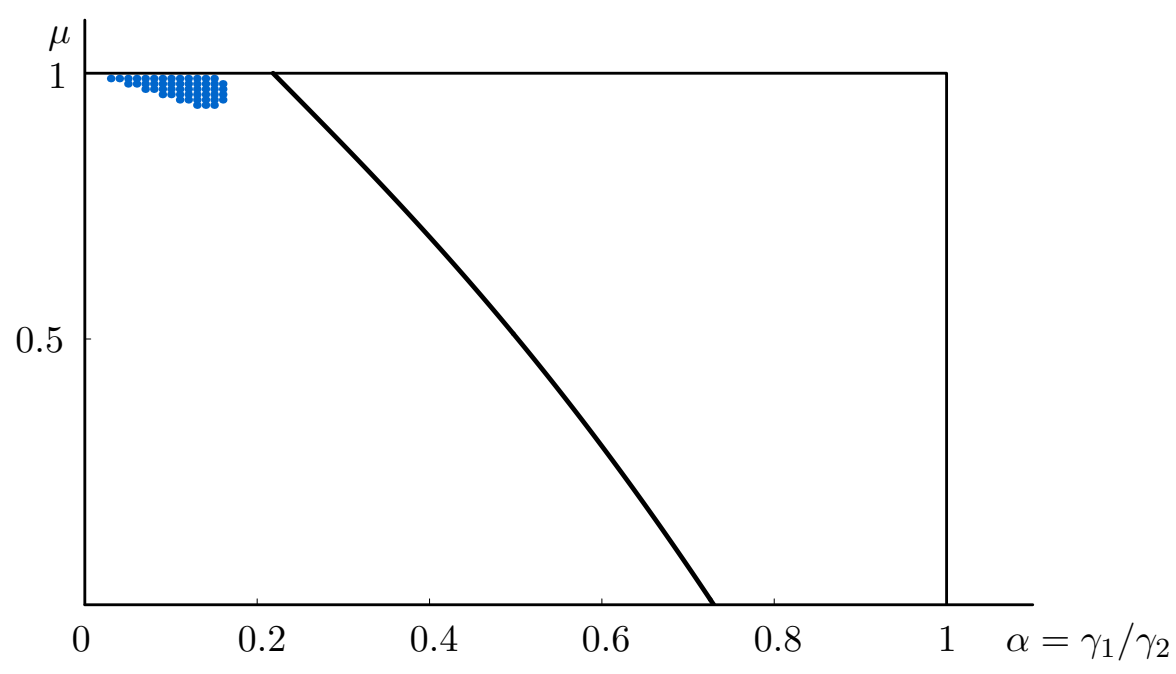

Figure 7: Comparison of Firm 2's net profit (num. simulations)

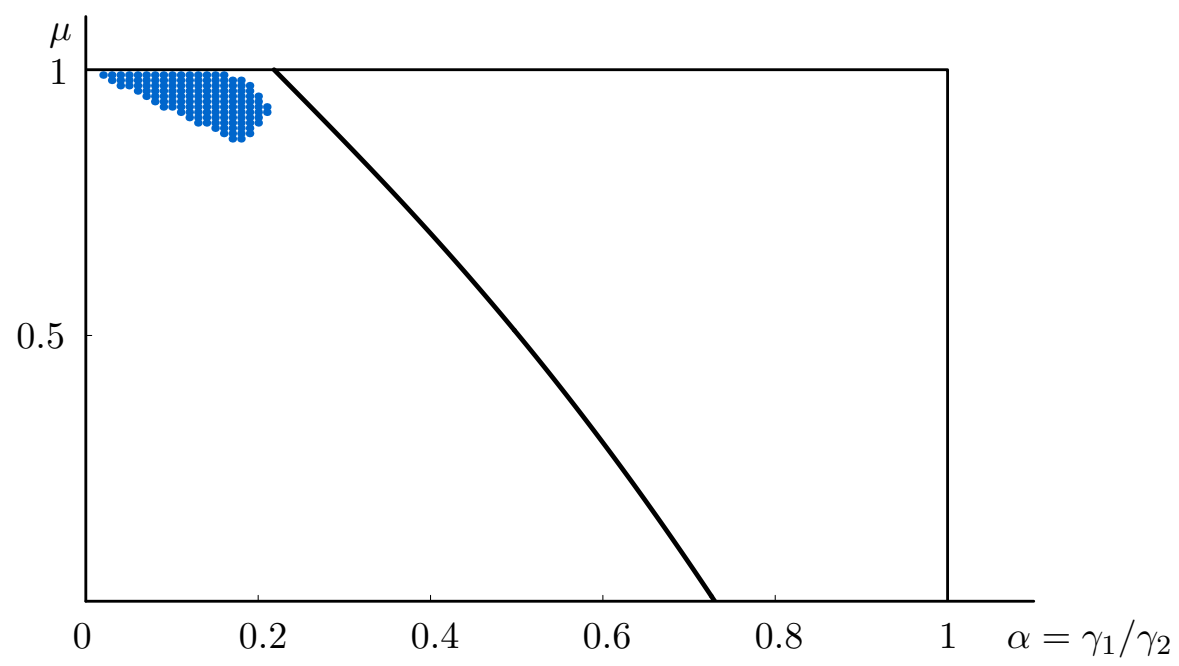

Figure 8: Comparison of Firm 2's gross profit (num. simulations) 


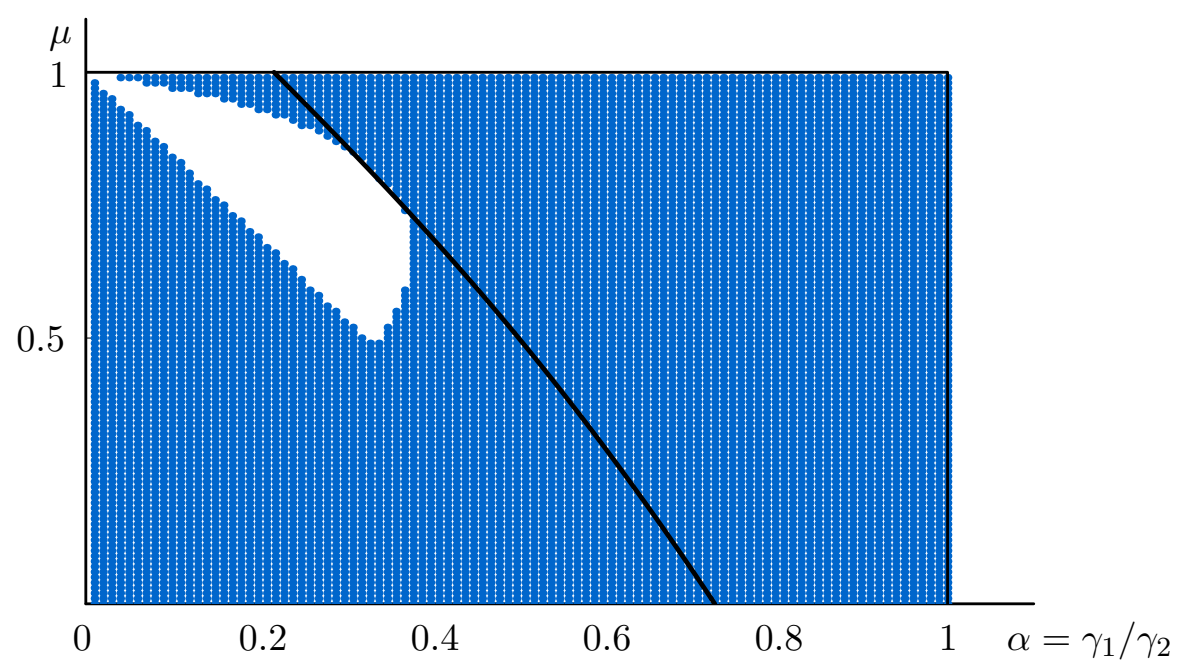

Figure 9: Comparison of the market size (num. simulations)

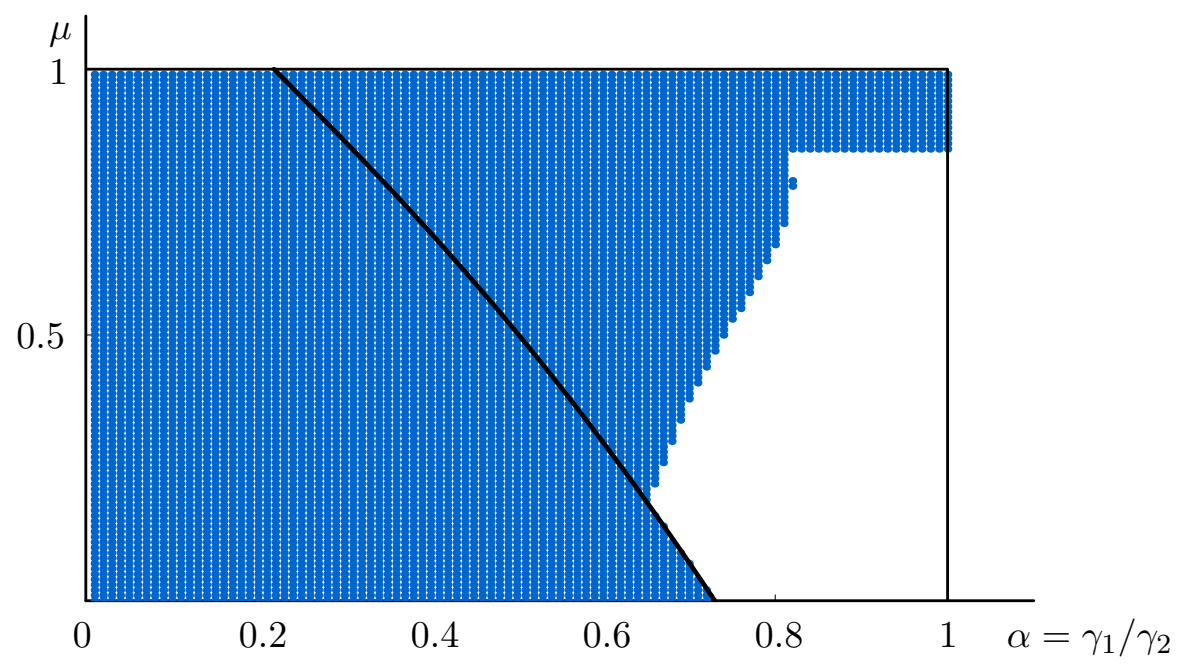

Figure 10: Comparison of the domestic welfare (num. simulations) 
Individual researchers, as well as the on-line and printed versions of the CERGE-EI Working Papers (including their dissemination) were supported from the following institutional grants:

- Economic Aspects of EU and EMU Entry [Ekonomické aspekty vstupu do Evropské unie a Evropské měnové unie], No. AVOZ70850503, (2005-2010);

- Economic Impact of European Integration on the Czech Republic [Ekonomické dopady evropské integrace na ČR], No. MSM0021620846, (2005-2011);

Specific research support and/or other grants the researchers/publications benefited from are acknowledged at the beginning of the Paper.

(c) Eugen Kováč, Krešimir Žigič, 2007.

All rights reserved. No part of this publication may be reproduced, stored in a retrieval system or transmitted in any form or by any means, electronic, mechanical or photocopying, recording, or otherwise without the prior permission of the publisher.

Published by

Charles University in Prague, Center for Economic Research and Graduate Education (CERGE) and

Economics Institute ASCR, v. v. i. (EI)

CERGE-El, Politických vězňŭ 7, 11121 Prague 1, tel.: +420 224005 153, Czech Republic.

Printed by CERGE-EI, Prague

Subscription: CERGE-EI homepage: http://www.cerge-ei.cz

Editors: Directors of CERGE and EI

Managing editors: Deputy Directors for Research of CERGE and EI

ISSN 1211-3298

ISBN 978-80-7343-135-8 (Univerzita Karlova. Centrum pro ekonomický výzkum

a doktorské studium)

ISBN 978-80-7344-124-1 (Národohospodářský ústav AV ČR, v. v. i.) 
CERGE-EI

P.O.BOX 882

Politických vězňů 7

11121 Praha 1

Czech Republic http://www.cerge-ei.cz 